\title{
Chronic obstructive pulmonary disease and lung cancer: underlying pathophysiology and new therapeutic modalities
}

Mathew Suji Eapen ${ }^{1}$, Philip M. Hansbro ${ }^{2,3}$, Anna Karin Larsson-Callerfelt ${ }^{4}$, Mohit K. Jolly ${ }^{5}$, Stephen Myers ${ }^{1}$, Pawan Sharma ${ }^{6,7}$, Bernadette Jones ${ }^{2,3}$, Md Atiqur Rahman ${ }^{2,3}$, James Markos ${ }^{1,8}$, Collin Chia ${ }^{1,8}$, Josie Larby ${ }^{1,8}$, Greg Haug ${ }^{1,8}$, Ashutosh Hardikar ${ }^{1,15}$, Heinrich C. Weber ${ }^{1,16,}$ George Mabeza $^{1,16}$, Vinicius Cavalheri ${ }^{9,10}$, Yet H. Khor ${ }^{11,12,13,14}$, Christine F. McDonald ${ }^{12,13,14}$, Sukhwinder Singh Sohal ${ }^{1}$

${ }^{1}$ Respiratory Translational Research Group, Department of Laboratory Medicine, College of Health and Medicine, University of Tasmania, Launceston, Tasmania, Australia, 7248

${ }^{2}$ School of Biomedical Sciences and Pharmacy, The University of Newcastle, Callaghan, Australia.

${ }^{3}$ Priority Research Centre for Healthy Lungs, Hunter Medical Research Institute, Lot 1 Kookaburra Circuit, New Lambton Heights, Newcastle and Centenary Institute and University of Technology Sydney, Australia.

${ }^{4}$ Lung Biology, Department of Experimental Medical Science, Lund University, Lund, Sweden ${ }^{5}$ Center for Theoretical Biological Physics, Rice University, Houston, Texas, United States

${ }^{6}$ Discipline of Medical Sciences, School of Life Sciences, University of Technology Sydney, Sydney, NSW, Australia, 2007,

${ }^{7}$ Woolcock Emphysema Centre, Woolcock Institute of Medical Research, University of Sydney, Sydney, NSW, Australia, 2037.

${ }^{8}$ Department of Respiratory Medicine, Launceston General Hospital, Launceston, Tasmania 7250, Australia.

${ }^{9}$ School of Physiotherapy and Exercise Science, Faculty of Health Sciences, Curtin University, Perth, WA, Australia

${ }^{10}$ Institute for Respiratory Health, Sir Charles Gairdner Hospital, Nedlands, WA, Australia

${ }^{11}$ Department of Allergy, Immunology and Respiratory Medicine, Alfred Health, Melbourne, Victoria, Australia.

${ }^{12}$ Department of Respiratory and Sleep Medicine, Austin Health, Heidelberg, Victoria, Australia.

${ }^{13}$ Institute for Breathing and Sleep, Heidelberg, Victoria, Australia.

${ }^{14}$ School of Medicine, University of Melbourne, Melbourne, Victoria, Australia.

${ }^{15}$ Department of Cardiothoracic Surgery, Royal Hobart Hospital, Hobart, Tasmania, Australia.

${ }^{16}$ Department of Respiratory Medicine, Tasmanian Health Services (THS), North West Hospital, Burnie, Tasmania, Australia

\section{Corresponding Author}

Dr Sukhwinder Singh Sohal

Respiratory Translational Research Group

Department of Laboratory Medicine, School of Health Sciences,

College of Health and Medicine, University of Tasmania

Locked Bag - 1322, Newnham Drive

Launceston, Tasmania 7248, Australia

Telephone number: +61363245434

Email: sssohal@utas.edu.au 


\begin{abstract}
COPD and lung cancer are major lung diseases affecting millions worldwide. Both diseases have links to cigarette smoking, and exert a considerable societal burden. People suffering from COPD are at a higher risk of developing lung cancer than those without COPD and are more susceptible to poor outcomes after diagnosis and treatment. Lung cancer and COPD are closely associated, possibly sharing common traits such as an underlying genetic predisposition, epithelial and endothelial cell plasticity, dysfunctional inflammatory mechanisms including the deposition of excessive extracellular matrix, angiogenesis, susceptibility to DNA damage and cellular mutagenesis. In fact, COPD could be the driving factor for lung cancer, providing a conducive environment that propagates its evolution. In the early stages of smoking, body defences provide a combative immune/oxidative response and DNA repair mechanisms are likely to subdue these changes to a certain extent; however, in patients with COPD with lung cancer the consequences could be devastating, potentially contributing to slower post-operative recovery after lung resection and increased resistance to radiotherapy and chemotherapy. Vital to the development of new-targeted therapies is an in-depth understanding of various molecular mechanisms that are associated with both pathologies. In this comprehensive review, we shall provide a detailed overview of possible underlying factors that link COPD and lung cancer and current therapeutic advances from both human and pre-clinical animal models that can effectively mitigate this unholy relationship.
\end{abstract}

Running head - COPD and lung cancer: understanding and treatments

Word Count $-10,082$ 


\section{Key points -}

There is consistent evidence that COPD and lung cancer share common pathological mechanisms. A greater understanding of these mechanisms may allow the development of new therapeutic targets.

Since $90 \%$ of cancers in the human body are of epithelial origin, it is possible that epithelial mesenchymal transition (EMT) is the link between COPD and lung cancer, being further exaggerated by associated pathologies such as angiogenesis, oxidative stress, infections and inflammation.

Inhaled corticosteroids suppress EMT in patients with COPD and decrease lung cancer risk in observational studies. If such effects are confirmed prospectively, EMT may be a possible new therapeutic target for management of both COPD and lung cancer, but this warrants further studies.

Small airway fibrosis and obliteration occur quite early in COPD. Therefore, it is important to understand mechanisms that are switched on early in the disease, in order to enable the possibility of early-personalised intervention.

Smoking cessation and exercise training should be promoted and considered as part of the multidisciplinary management of patients with both COPD and lung cancer. 


\section{COPD and lung cancer}

Chronic obstructive pulmonary disease (COPD) is a systemic inflammatory condition associated with several comorbidities, including lung cancer. It is a major cause of global morbidity and mortality with 328 million affected worldwide and 3.5-4 million deaths annually. According to the World Health Organization (WHO) COPD is currently the third leading cause of death globally and within 15 years is expected to become the leading cause of death. [1]. Cigarette smoke is the major etiological factor but air pollution and smoke from biomass fuels are also major contributors, especially in low- and middle-income countries [1]. Smokers with COPD are twice as likely to develop lung cancer as smokers without COPD, and lung cancer is a common cause of death in COPD [2]. Patients with lung cancer and concomitant COPD have a worse survival than patients with lung cancer without COPD [3-5]. Although an association between both of these diseases has been established for decades, therapeutic approaches for preventing lung cancer in patients with COPD remain limited. Co-existing COPD may limit treatment options for lung cancers and thus must be assessed and managed in a timely manner. Lung cancer is one of the most common forms of cancer in the world, with 1.8 million new cases detected annually (as of 2015) and 1.6 million deaths worldwide annually [6]. The current 5 year average survival rate (18.6\%) for patients with lung cancer is much lower than for other leading causes of cancer, with regional differences being attributed to variations in treatment and diagnostics [6,7]. Worldwide, smoking prevalence has steadily increased and is currently the major contributor, with about $80 \%$ of lung cancer related deaths linked to smoking in the United States and France [8], 61\% in Asia and 40\% in sub-Saharan Africa. Second hand tobacco smoking (SHS) is also a risk factor, with over 21,400 lung cancer deaths in non-smokers annually attributed to SHS [9]. In low and middle income countries, indoor air pollution mostly due to combustion of wood or coal used for cooking and heating purposes, is another important risk factor [10]. The Australian Institute of Health and Welfare [11] found that lung cancer was the leading cause of death for both male and female Australians followed by colorectal, breast, prostate, and pancreatic cancers. In 2017, nearly 12,500 Australians were diagnosed with lung cancer, which is 34 people every day [11]. Lung cancer was also responsible for the highest overall burden among cancers [11].

Lung cancers are broadly classified into two major types; non-small-cell lung cancer (NSCLC) and small-cell lung cancer (SCLC) $[12,13]$. NSCLC constitutes $85 \%$ of all lung cancers, and is further characterised into squamous cell carcinoma (SqCC), adenocarcinoma, and large cell 
carcinoma. While SqCC typically arises from large airway bronchial squamous epithelium [14], adenocarcinoma (40\% of all cancers) arises from the secretory (glandular) cells that are located in the distal epithelial lining of the lung bronchi [15]. Although adenocarcinoma is most often found in smokers, it is also the more prevalent variant of NSCLC in non-smokers. Largecell carcinoma consists of large-sized cells that are anaplastic and arises from large airways [16]. In addition to these common subtypes of NSCLC, there are also other variants, including bronchoalveolar or "lepidic predominant adenocarcinoma", mixed and undifferentiated carcinomas.

Small-cell lung cancer (SCLC) usually arises centrally in the chest (large airways or lymph nodes) [17]. It contains dense neurosecretory granules and is associated with paraneoplastic syndromes at presentation such as inappropriate secretion of antidiuretic hormone. SCLCs have traditionally been staged into limited and extensive stage disease [18]. They are divided into typical and atypical and can grow either in the airways or in the lung periphery $[17,18]$. Like SCLC, carcinoid tumours are characterised as neuroendocrine tumours, which are commonly located in the gastrointestinal tract, and less commonly in the lung [19].

\section{Chemoprevention for lung cancer in COPD}

To date, smoking cessation is the only proven effective approach for preventing lung cancer in patients with COPD [20-22]. In view of the potential shared mechanism of chronic inflammation in both diseases, the chemoprotective effect of anti-inflammatory agents in COPD population has been assessed. Three retrospective studies of patients with COPD from different countries found a reduced risk of lung cancer in those using inhaled corticosteroids [23-25], with a negative dose-response relationship between the dose of inhaled corticosteroids and the risk of developing lung cancer [23-25], Table 1. A meta-analysis of seven randomized controlled trials assessing the effects of inhaled corticosteroids in COPD $(n=5085)$ revealed a trend towards decreased lung cancer mortality in the treatment group compared to the placebo group [26]. In contrast, inhaled corticosteroids have not been shown to exert significant chemopreventive effects in smokers with premalignant lung lesions [27, 28]. The exact mechanisms through which inhaled corticosteroids exert these apparent anti-cancer effects are not clear, however, we will discuss potential mechanisms later in this review. 
Statins have also been shown to have a possible role in preventing lung cancer in patients with COPD [29]. A retrospective cohort study of more than 40,000 patients with COPD reported that the use of statins reduced lung cancer risk by 63\% [30]. However, neither inhaled corticosteroids nor statins have been evaluated in prospective controlled trials. Given the lack of definitive evidence, neither agent should be used solely for their potential chemoprotective effects in patients with COPD. Chemoprevention for lung cancer has also been investigated in ever-smokers who may have COPD. Pre-clinical and epidemiologic studies indicated potential protective roles of antioxidants in preventing cancers [31]. However, randomised controlled trials on lung cancer prevention using antioxidant supplements in ever-smokers have been disappointing. Neither combination supplementation with alpha-tocopherol, beta-carotene and retinol, nor the individual components was found to reduce lung cancer risk in major randomised controlled trials, the Alpha-Tocopherol, Beta-Carotene Cancer Prevention study (ATBC) [32] and the Beta-Carotene and Retinol Efficacy trial (CARET)[33]. Indeed, the ATBC and CARET studies, which included over 47,000 ever-smokers in total, consistently showed an increased risk of lung cancer with beta-carotene supplementation in ever-smokers $[32,33]$. A recent prospective cohort study of vitamin B supplementation for lung cancer found that high-dose vitamin B6 or B12 supplementation increased lung cancer risk in male smokers [34]. The mechanism of increased lung cancer risk with micronutrient supplementations is unclear. Some of the recent studies are listed in.

\section{Impact of COPD and lung cancer on exercise capacity}

Exercise capacity in patients with chronic respiratory diseases such as COPD and/or lung cancer is impaired and often limited by symptoms such as dyspnoea and leg fatigue [35]. In patients with COPD, exercise intolerance can result from one or a combination of the following: ventilatory limitation, impaired gas exchange, atrophy of peripheral muscles and/or peripheral muscle weakness and cardiac dysfunction [35]. In those with concomitant lung cancer, exercise capacity can be further reduced by the tumour(s) itself, which disrupts pulmonary mechanics and gas exchange, as well as a result of the lung cancer treatment, which can include lung resection, chemotherapy, radiotherapy and other options [36].

Exercise capacity of patients with COPD and/or lung cancer can be measured using either laboratory-based exercise tests (such as the maximal incremental cardiopulmonary exercise test $[\mathrm{CPET}]$ ) or field-based exercise tests (such as the six-minute walk test [6MWT] and 
incremental shuttle walk test [ISWT]). The importance of assessing exercise capacity in these populations is well-established. In both patients with COPD and patients with lung cancer the peak rate of oxygen consumption ( $\mathrm{VO}_{2}$ peak) measured during a CPET has been shown to be a strong predictor of mortality $[37,38]$. Furthermore, $\mathrm{VO}_{2}$ peak measured before surgery is a strong predictor of postoperative pulmonary complications for patients undergoing lung resection for NSCLC [37]. Of note, performance during field-based walking tests also has prognostic implications. A systematic review of 13 studies reported an association between six-minute walk distance and mortality in patients with COPD [39]. In patients undergoing lung resection for NSCLC, poor performance in the 6MWT or the ISWT before surgery is associated with an increased risk of postoperative pulmonary complications [40, 41].

\section{The role of exercise training/therapy}

Exercise training has been shown to improve exercise capacity in both patients with chronic lung diseases and patients with different types of cancer. In fact, exercise training, which is the cornerstone of pulmonary rehabilitation, is an integral component for management of patients with COPD. [42] When compared to COPD, research on exercise training in patients with lung cancer is in its infancy. However, recent studies have demonstrated its value across the whole lung cancer continuum, especially in patients with NSCLC [43-46].

Pulmonary rehabilitation, including exercise training, should be offered to patients with stable COPD or following an exacerbation of their disease [35, 47]. A Cochrane review of 65 randomised controlled trials (RCTs) concluded that pulmonary rehabilitation significantly improves exercise capacity, health related quality of life (HRQoL), and symptom control in patients with COPD [48]. Of note, there was no difference in outcomes between exercise training only and more complex pulmonary rehabilitation programmes [48]. Pulmonary rehabilitation following an exacerbation of COPD has been shown to reduce hospital readmissions [49]. In patients with early stage NSCLC, both preoperative and postoperative exercise training programmes have been demonstrated to be effective at improving health outcomes $[50,44]$. However, despite the growing evidence of the benefits of exercise training in this population, referral of such patients to exercise training programmes is still uncommon [51]. A standard pulmonary rehabilitation exercise program is 6 to 8 weeks in duration. To minimise surgical delay, a modified exercise program of shorter duration with more frequent sessions is more appropriate for patients with lung cancer. Preoperative exercise training 
predominantly comprises aerobic training and is usually conducted whilst patients await surgery. In most studies to date, this timeframe ranged between 1 to 4 weeks [44]. In both cohort studies and a systematic review of RCTs, short-term (2 to 4 weeks) intensive preoperative pulmonary rehabilitation (or 'pre-habilitation') significantly improved baseline lung function, exercise capacity and symptoms in patients with lung cancer [52, 53, 44]. In addition, pre-operative exercise training was associated with improved lung function recovery after surgery and reduced post-operative pulmonary complications $(51,73)$. In a study by Licker et al that investigated the effectiveness of preoperative exercise training on postoperative outcomes in people undergoing lung resection for NSCLC, independent predictors of postoperative pulmonary complications were preoperative peakVO2, pre-operative exercise training, and COPD [56, 57].

A decline in exercise capacity and lung function, both important prognostic factors, is commonly observed following lung resection for NSCLC [54, 55, 37]. Postoperative exercise training programmes should be tailored to improve exercise capacity and health outcomes that may have been negatively affected by the lung resection. The usual duration and characteristics of the postoperative programme are derived from the COPD pulmonary rehabilitation literature. Programmes range between 8 to 12 weeks; with sessions 2 to 3 times/week, including both aerobic and resistance training. Postoperative exercise training has been shown to improve exercise capacity ( $\mathrm{VO}_{2}$ peak and six-minute walk distance), [50, 43, 45] total muscle mass[45] and HRQoL [45].

In patients with advanced lung cancer exercise training programmes should aim to prevent deterioration in important clinical outcomes, control symptoms and maximise independence. This is an area of growing interest amongst researchers and clinicians, and there are several RCTs being conducted to investigate effectiveness of exercise training in this population [5658]. To date, exercise training has been shown to be feasible and safe in patients with advanced lung cancer [59].

\section{Perioperative care for surgical candidates}

Surgical resection remains the treatment of choice for patients with early-stage NSCLC and co-existing COPD who have adequate physiologic reserve. Patients with COPD have higher post-operative morbidity and mortality following lung resection [60-63]. The degree of lung 
function impairment correlates with post-operative complications. Patients with lung cancer may have undiagnosed COPD or under-treated COPD. Timely assessment and management of COPD during the perioperative period are important for optimisation of baseline lung function and fitness in order to minimise potential surgical morbidities. Evidence regarding the shortterm effects of these approaches for improving perioperative outcomes is limited.

Long-acting bronchodilators, including long-acting muscarinic antagonists (LAMAs) and long-acting beta2-agonists (LABAs), are the mainstay therapy for long-term management of patients with COPD. Both agents have been shown to improve dyspnoea, lung function, exercise capacity and health-related quality of life, and to reduce exacerbation rate in patients with stable COPD [64, 65]. Perioperative commencement of long-acting bronchodilators, within 1 to 2 weeks prior to thoracic surgery significantly improved pre-operative lung function $[66,67]$. Initiation of LAMAs or LABAs prior to surgery has also been shown to reduce postoperative cardiorespiratory complications in patients with lung cancer [68, 69]. A randomized controlled trial by Suzuki et al demonstrated that the perioperative use of combined LAMA and LABA improved post-operative lung function and health-related quality of life in patients with COPD, particularly in those with moderate-to-severe disease [70].

Cardiovascular complications are common following thoracic surgery, particularly in those with COPD who are at high risk of cardiovascular events $[62,71]$. Concerns have been raised that cardiovascular adverse events could be associated with the use of long-acting bronchodilators. Muscarinic receptor antagonists have been associated with cardiovascular events in observational and clinical trials $[68,72]$. However, an increased incidence of postoperative cardiac complications, including arrhythmias, with the use of LABAs and LAMAs has not been reported in retrospective studies $[68,72]$.

Although long-term use of inhaled corticosteroids has been shown to reduce exacerbations in patients with moderate-to-severe COPD, they have also been demonstrated to be associated with an increased risk of pneumonia [73-75] [76-79]. A retrospective study by Yamanashi et al revealed no association between perioperative use of inhaled corticosteroids and postoperative respiratory complications [80]. Further, addition of inhaled corticosteroids to dual long-acting bronchodilators was associated with improved pre-operative lung function and reduced post-operative pulmonary complications in patients with COPD [67]. 
To achieve the best outcomes for patients with lung cancer and COPD, optimising management of COPD should be integrated into routine care. Smoking cessation and short-term intensive preoperative pulmonary rehabilitation should be advocated. Warner et al reported that patients who had stopped smoking for two months or less had a pulmonary complication rate almost four times that of patients who had stopped for more than two months. They recommend at least two months of smoking cessation should occur to maximize the reduction of postoperative respiratory complications [81]. Kuri et al reported that preoperative smoking cessation of longer than three weeks has the potential to reduce the incidence of impaired wound healing among patients who have undergone reconstructive head and neck cancer surgery [82]. Very little work has been is done in this area therefore, more studies looking at the beneficial effects of smoking cessation are warranted. Dual bronchodilation with LAMA and LABA is the preferred therapy for improving patients' baseline clinical status. Pre-operative use of inhaled corticosteroids may have additional clinical benefits, particularly in those with moderatesevere COPD.

\section{Lung cancer radiotherapy}

Radiotherapy improves loco-regional disease control and survival in patients with lung cancer. However, radiation pneumonitis is a concerning side effect of thoracic radiotherapy, consequent upon the lungs' exquisite sensitivity to ionizing radiation. The incidence of radiation pneumonitis in lung cancer varies depending upon irradiation techniques and regimens. The reported incidence of clinically symptomatic radiation pneumonitis is up to $17 \%$ among patients undergoing radical radiotherapy [83, 84]. Patients with lung cancer are commonly being treated using newer irradiation techniques such as intensity-modulated radiotherapy (IMRT) and stereotactic body radiotherapy (SBRT) which provide more optimal radiation dose distribution and lower impact to normal tissue. In comparison to conventional radiotherapy, IMRT uses an involved-site technique to alter the intensity of radiation in different parts of a single radiation beam. On the other hand, SBRT, also referred to as stereotactic ablative radiation, administers higher doses of radiation over fewer fractions to an accurately delineated target. The use of IMRT has been shown to reduce rates of severe pneumonitis when compared to conventional radiotherapy (3.5\% vs $7.9 \%)$ [85]. Clinically significant radiation pneumonitis develops in fewer than $10 \%$ of patients receiving SBRT for lung cancer $[86,87]$. 
Data are conflicting regarding the effect of COPD on the risk of radiation pneumonitis. Previous retrospective studies reported that COPD was associated with an increased incidence of radiation pneumonitis, including in those who received SBRT [88, 89]. However, in patients with lung cancer treated with radiotherapy, patients with severe COPD experienced milder radiation pneumonitis compared to those with normal lung function or milder COPD [90, 91]. It is possible that the lack of lung tissue associated with the presence of emphysema in patients with severe COPD reduces the potential for radiation-induced lung toxicity. Systemic glucocorticoids remain the mainstay therapy for patients with symptomatic radiation pneumonitis, with limited evidence suggesting that high-dose inhaled budesonide $800 \mu \mathrm{g}$ twice daily may be a potential alternative therapeutic option [92].

Other local therapies such as radiofrequency ablation (RFA) and thermal ablative therapies have been used for treatment of lung cancer and other types of cancers [93]. In a retrospective, case-controlled observational study, Chi et al reported that both RFA and microwave ablation were equally effective and safe for patients with primary and metastatic lung tumours. Ablation was successfully completed in all patients with no procedure-related death. Mu and colleagues reported that CT-guided percutaneous RFA appeared to be a safe and effective treatment option for lung malignancies adjacent to the pericardium [94].

\section{Systemic therapies}

While systemic chemotherapy is the standard of care for patients with advanced lung cancer, the recent development of tyrosine kinase inhibitors (TKIs) and immunotherapy has revolutionised management for these patients. Tyrosine kinase inhibitors are small molecule inhibitors of enzymes that regulate cellular growth factor signalling, while immunotherapies are monoclonal antibodies directed against immune checkpoint proteins to enhance endogenous immune responses against tumour cells [95]. The current approach to systemic therapies in lung cancer focuses on tailoring treatment choice according to tumour histology and molecular profiles. Compared to chemotherapy, TKIs and immunotherapies show promising results with sustained responses in selected patients. Although new systemic therapeutic agents are generally less toxic than systemic chemotherapy with favourable safety profiles, their unique mechanisms of action can result in a different array of side effects. 
Drug-related pneumonitis has been reported with the use of TKIs and immunotherapies. Systematic reviews found that the incidences of drug-related pneumonitis were $1.2 \%$ for epidermal growth factor receptor (EGFR) TKIs, $2.1 \%$ for anaplastic lymphoma kinase (ALK) TKIs and 1.3-3.6\% for immunotherapies [96-98]. The mortality rates of drug-related pneumonitis were $22.8 \%$ for EGFR TKIs and 9\% for ALK TKIs. Although COPD per se has not been identified as a risk factor for drug-induced pneumonitis, cigarette smoking is associated with an increased incidence of pneumonitis [99]. Interstitial lung disease, another risk factor for drug-induced pneumonitis, not uncommonly co-exists in patients with COPD [100]. In addition, long-term use of inhaled corticosteroids may increase the risk of Pneumocystis jiroveci pneumonia in patients with lung cancer and co-existing COPD who are treated with systemic therapies [101, 102]. This possible risk should be weighed against any potential improvement in lung function or symptoms achievable through the use of inhaled corticosteroids in individual patients, after considering other risk factors for opportunistic infection. It is important to monitor symptoms and lung function in patients with COPD and lung cancer who receive these agents in order to detect possible drug-related adverse effects early.

As immunotherapies can modulate T-cell response via inhibition of immune checkpoints, they may be of potential therapeutic value for COPD. There are emerging data suggesting a potential role of dysregulated immune checkpoints leading to excessive T cell response in COPD [103]. Given the complex interplay of various inflammatory pathways in COPD, further investigations are required before translating this knowledge into clinical management.

\section{Mechanisms linking COPD and lung cancer}

The major mechanisms linking COPD and lung cancer are likely related to common traits of both diseases, such as: oxidative stress, inflammation, genetic predisposition, epigenetics in lung cancer and COPD, extracellular vesicles (EVs), epithelial-mesenchymal transition (EMT), endothelial to mesenchymal transition (EndoMT), extracellular matrix (ECM) and angiogenesis (Figure 1). COPD has been shown to be a risk factor for lung cancer [104]; COPD patients are at a six-fold higher risk of developing lung cancer as compared to smokers with normal pulmonary function [105]. Here, we discuss common mechanisms shared by both of these diseases. 


\subsection{Oxidative stress}

Cigarette smoke contains more than 4000 different types of poisonous chemicals and is known to generate greater than 1000 oxidants per puff; oxidative stress can cause damage to lung tissue by inducing cellular proteomic and transcriptomic changes. Reactive oxygen species (ROS) and reactive nitrogen species (RNS) are among the more potent molecular candidates that interact with vital cellular organelles such as mitochondria and endoplasmic reticulum to cause potentially devastating imbalances in cellular metabolism.

In both COPD and lung cancer, there is substantial evidence that points to increased ROS and RNS activity causing systemic cellular breakdown as well as inducing irreversible DNA damage. ROS generated through cigarette smoke directly affects inflammatory cells, systematically reducing their ability to mount an immune response to infections as well as obliterating cancer cells. In smokers and COPD patients Morlá et al [106] observed that peripheral lymphocytes had shorter telomere length compared to normal healthy subjects, thus leading to a shorter cellular lifespan. This has been attributed to ROS, which are known to accelerate the process of cellular aging. Similar studies by Ceyalan et al. [107] also identified that circulating leukocytes in this population had severely damaged DNA with a considerable increase in lipid peroxidation mutagen markers such as plasma malondialdehyde and TBAreactive substances. Thus, decreasing life span and DNA damage in lymphocytes in smokers and in patients with COPD make them more susceptible to cancer, in part due to weakened immune response resulting in inability to remove transformed or mutated cells. This fits with our recent findings of decreases in key inflammatory cell populations in early COPD [108], thus increasing such individuals' susceptibility to respiratory infections as well as to cancer [109-111, 78, 79].

In lung cancer, elevated levels of ROS induce single or double-stranded DNA breaks and abnormal DNA crosslinking [112]. This would result in arrest or induction of unwarranted transcription, replication errors, and genomic instability, all of which could lead to cancer induction and spread. In fact, common toxic oxidative chemicals from smoking such as B(a)P diol epoxide (BPDE) cause irreversible damage to the DNA by forming DNA adducts through covalent binding or oxidation. The formation of BPDE-DNA adducts, if left unrepaired by nucleotide excision repair mechanisms, can block the transcription of essential genes, leading to unwarranted cellular effects [113]. Genome-wide association studies (GWAS) have also 
revealed suboptimal DNA repair capacity (DRC) as a major determinant for genetic susceptibility to lung cancer although there is considerable inter-individual variation in DRC partly due to the variability in DNA repair genes [114].

Increased ROS levels also induce cellular senescence via DNA damage, arrest cellular growth and alter cellular function. Senesced immune cells have activated protein complexes leading to a condition termed senescence-associated secretory phenotype (SASP) which produces phlogogenic substances such as IL-1, IL-6, and IL-8 [115]. The cytokines produced are potent attractors and activators of innate immune cells, which cause tissue damage by producing even more oxidizing molecules, released mainly to destroy pathogens which are not necessarily present [116]. In NSCLC, cytokines that are enhanced in SASP complex are also known to be markers of prognosis. Interestingly, among them IL-6 is known to initiate growth and spread of lung cancer in mouse models, which has been attributed to the IL-6/STAT3 pathways [117].

The impact of ROS and their relationship with smoking, lung cancer and COPD is of paramount importance and further understanding the mechanisms underlying these relationships could possibly provide new therapeutic opportunities for early interventions.

\subsection{Inflammation}

Airway inflammation is known to play a critical role in COPD and cancer [118]. Over many years, the literature has provided important insight into the increases of both innate and adaptive immune cells in both bronchoalveolar lavage (BAL) and sputum samples in COPD $[119,120]$. However, evidence suggests substantial contradiction about the actual picture of the type of inflammation in the airway wall wherein hypo-cellularity [121] or cellular dysfunctionality/abnormalities are observed [120].

It remains to be deciphered whether inflammation plays a causal role in enhancing mutations in lung cancer. However, inflammatory factors can enhance the progressive capacity of cancer cells. For examples, increased activation of NF- $\mathrm{BB}$ activity results in lung inflammation and substantial pro-tumorigenic effect. The effector cell population that mediates tumorigenicity is the macrophages, which could be recruited to the lungs because of epithelial cell induced NF$\kappa \mathrm{B}$ activation [122]. A number of studies have reported increases in alveolar and luminal macrophages in smokers with both normal lung function and COPD when compared to non- 
smoker controls [123]. Further, sub-phenotyping the macrophages in these patients groups also revealed predominantly M2 macrophages, with increased expression of the phagocytic receptor CD163/CD206 [124, 120]. This increase in M2 macrophages switch was identified to be promoted by pro- Th2/M2 cytokines such as IL-4, IL-10, IL-13, CCL22, and IL-6 among others [120]. Interestingly, in the tumour microenvironment itself, tumour-associated macrophages were shown to be predominantly M2 as well, which suggests that polarization of macrophages observed in mild-moderate COPD patients could be pro-tumorigenic [125]. A recent metaanalysis with over 2500 NSCLC patients [126], observed that M2 macrophages were indeed the dominant macrophage phenotype and specifically patients' survival was attributed to the dominant sub-type of macrophages in the tumour microenvironment [126, 125]. The authors concluded that patients with larger numbers of M2 macrophages had lesser chances of survival than those with M1 macrophage phenotype. Almatroodi et al demonstrated that differences in M1 and M2 predominance varied according to NSCLC subtype [127].

Other than macrophages, lymphocytes, especially cytotoxic CD8+ T cells, also form an important link in both COPD and lung cancer. Interestingly, CD8+ T cells are the dominant $\mathrm{T}$ cell phenotype in patients with mild-moderate COPD over CD4+ T cells and this dominance may be partly due to increased susceptibility of COPD patients to viral infections [119]. Recently, McKendry et al [128] provided evidence of increased expression of programmed cell death (PD)-1 in CD8+ T cells and the ligands PD-L1 on macrophages in ex-vivo samples from patients with mild-moderate COPD. The interaction between PD-1 and its ligand PD-L1 induces cell cycle arrest resulting in T cell anergy. Further, external administration of influenza virus led to an increased propensity of dysfunctional CD8+ T cells, estimated by their decreased ability to degranulate [128]. Similarly, increased expression of PD-1 on CD8+ T cells was found to be higher in peripheral blood of patients with NSCLC- and their interaction with PDL1 in the tumour milieu is now an established target for antibody based therapeutic interventions such as pembrolizumab in advanced stages of cancer $[129,130]$. These studies suggest that orientation of immune cell expression patterns towards lung cancer is observed quite early in both smokers and patients with COPD and that detecting these changes could help to design more effective future diagnostics and therapies.

\subsection{Role of extracellular vesicles}

Extracellular vesicles (EVs) are small membranous vesicles that are secreted or shed by cells. In humans, EVs can be detected in body fluids including blood, urine, saliva, breast milk, 
ascites, and cerebrospinal fluid, among others. They are categorized as exosomes, ectosomes, microvesicles, or apoptotic bodies depending upon size [131]. The size of EVs varies from 30$1000 \mathrm{~nm}$, with exosomes being the smallest (30-100 nm) and larger apoptotic bodies ranging up to $100 \mathrm{~nm}$ [132]. Exosomes can play a crucial role in both COPD and lung cancer. EVs in general, are known to actively regulate tumour microenvironment (TME) by directly altering the immune response or through modulating epithelial transition, fibroblast activation or angiogenesis [133]. Changes to the TME could take place through selective transfer mechanisms and would ideally involve both proteins and nuclear materials such as RNA. For example, McCready et al [134] observed that HSP90 $\alpha$, in tumour associated secretory exosomes, increases invasiveness of cancer cells through the activation of plasmin and annexin-II. HSP90 $\alpha$ protein is abundant in patients with COPD and acts as a potent biomarker along with HSP 27 and 70 [135]. It potentiates EMT in several forms of cancer [136], a phenomenon which is also active in patients with early stage COPD, pointing towards a possible association. Similar to transfer of proteins, miRNA-containing exosomes can be a determining factor in both lung cancer and other chronic lung disease [137]. MiRNAs are known to selectively inhibit or silence the mRNA translational process, thus acting as an important cellular modulator. For example, the miR-200 family of miRNA can actively inhibit TGF- $\beta 1$ induced EMT activity in airway epithelial cells [138] and forms a double negative feedback loop with a family of EMT-inducing transcription factors, ZEB [139]. Studies in both lung cancer and COPD suggest a significant reduction in cellular miR-200 and an increase in extracellular exosomal miR-200 [140, 141]. The decrease in cellular miRNA suggests active cellular expulsion through exocytosis of this essential regulator, leading to an increase in epithelial cell plasticity and mobility. Although recent studies have implicated EV in the pathophysiology of lung cancer, a connection to COPD could lead to the discovery of potential biomarkers and novel therapeutic interventions for management of lung cancer [142].

\subsection{Extracellular matrix (ECM) and proteinases}

ECM has important roles in maintaining tissue functionality and stability and in regulating cell activities. The ECM is organised in two main structural types: 1) basement membranes in epithelia and endothelia and 2) interstitial network of fibrous proteins, glycosaminoglycans and matricellular proteins that provides structural support for cell types in the lung and maintains three-dimensional appearance and biomechanical characteristics [143, 144]. Key ECM proteins maintaining tissue integrity are, for example, elastin, collagens and specific 
proteoglycans. The ECM is also an important storage source for different growth factors and cytokines, which are crucial for cell differentiation and proliferation [145, 146]. One of the major producers and regulators of ECM are the fibroblasts. These cells synthesise large amounts of matrix components, different growth factors and inflammatory mediators. Fibroblasts may thereby have important modulatory roles in autocrine and paracrine fashion in regulating ECM in different lung compartments, and in giving rise to pathological changes in the ECM of lung cancers, such as increased collagen expression, altered collagen cross-linking and subsequent increase in tissue stiffness [144].

SCLC is encircled by an extensive stroma of ECM and tumorigenicity has been shown to be enhanced by SCLC cells binding to the ECM, creating a highly specific microenvironment [147]. Activated fibroblasts, known as cancer-associated fibroblasts (CAFs), play an essential role in tumour progression by substantially remodelling tumour ECM, suppressing immune response and releasing tumour growth-promoting factors [148]. Thus, the tumour ECM provides a specialised microenvironment, favouring proliferation and metastasis and inhibiting apoptosis of tumour cells. Encapsulating tumour stroma can confer resistance to chemotherapy [147]. In COPD, there are processes ongoing in parallel with excessive ECM being produced and manifested as both peribronchial fibrosis and degraded ECM in the alveoli resulting in emphysema [145]. Alterations in elastic fibres, fibronectin, collagens, tenascin- $\mathrm{C}$ and versican have been identified throughout all lung compartments in patients with moderate COPD [149] and there are pronounced alterations in proteoglycan synthesis from central and distallyderived lung fibroblasts from patients with severe COPD [150]. Importantly, distal lung fibroblasts from patients with severe COPD appeared to have altered fibroblast function and defective repair mechanisms in the ECM structure of the collagen network assembly in response to the prostacyclin analogue iloprost, perhaps thereby affecting emphysema progression [151].

The homeostasis of ECM is tightly regulated by matrix metalloproteinases (MMPs) and specific tissue inhibitors of metalloproteinases (TIMPs) [152] [153]. These proteases target the ECM for degradation, which alters tissue architecture and causes the release of ECM derived chemoattractant signals known as matrikines, which can propagate inflammation [154]. MMPs, especially MMP-2 and MMP-9, are implicated in the degradation of ECM in basement membranes, which facilitates tumour invasion and metastasis. MMP-2 is expressed in both normal and tumour tissues, whereas MMP-9 is largely induced during tissue remodelling [153]. 
In cancer, MMP-9 overexpression may contribute to stimulating tumour vascularisation and tumour cell proliferation [155]. An overproduction of MMPs in intratumoral stromal cells is associated with poor prognosis of NSCLC $[153,155]$. Interestingly, the proteoglycan decorin, which is essential for collagen fibrillogenesis, interacts with MMPs and can act as a tumour suppressor by attenuating tumour growth, migration and angiogenesis [156]. In COPD, there is an imbalance between MMPs and TIMPs, which causes an overproduction of MMPs. Increased MMP activity and neutrophil elastase correlate with COPD pathology and MMP-9, in particular, has a major role in the development of emphysema [157]. The degrading of ECM by MMPs may also increase the bioavailability of growth factors, cytokines and receptors stored in the ECM. MMP-9 also increases as part of the EMT process in smokers and people with COPD [158].

\subsection{Angiogenesis}

Smoking, a key factor in the development of both COPD and lung cancer, results in hypoxia, which is an important driver of angiogenesis [159]. Nicotine may increase hypoxia-inducible factor (HIF)-1 in NSCLC and promote tumour angiogenesis [160, 161]. Vascular endothelial growth factor (VEGF) is one of the most important factors promoting angiogenesis and vascular remodeling processes [162]. In cancer, tumour progression from a benign to a malignant stage is often related to an angiogenic switch - which involves triggering and development of a vascular network that is actively growing and infiltrative [163]. As tumours increase in size their microenvironment becomes hypoxic and HIF is activated, which induces expression of MMPs and VEGF, leading to progression and invasion. VEGF correlates with progression, metastasis and poorer prognosis [164]. Proteinases induce the release of growth factors such as TGF- $\beta$ and VEGF, which play a pivotal role in tumorigenesis and metastasis of lung cancer. Cancer associated fibroblasts have well-established pro-angiogenic functions in tumours and are, together with other hypoxic cancer cells, major sources of secreted VEGFA, which initiates tumour angiogenesis through vascular endothelial growth factor receptor-2 (VEGFR-2), expressed on endothelial cells [165]. During hypoxic conditions, prostacyclin synthase expression was up-regulated in human lung fibroblasts, promoting VEGF synthesis in tumours [166].

Pulmonary vascular remodeling is common in COPD [162] and comorbidities including cardiovascular disease have negative impacts on COPD prognosis [167]. In COPD, airflow obstructions in small airways and destruction of alveolar capillaries result in decreased oxygen 
transport and alveolar hypoxia. This causes an activation of HIF, which promotes angiogenesis via VEGF [168]. Interestingly, VEGF is synthesised in high amounts by distally derived lung fibroblasts and induced by both prostacyclin and TGF- $\beta$. In a recent study, synthesised VEGF acted in an autocrine fashion by increasing ECM synthesis, migration and proliferation of human lung fibroblasts [169]. However, in this study there were no significant differences in synthesised VEGF levels between fibroblasts from non-smoking control subjects and those from patients with severe COPD. In line with these findings, expression of VEGF in pulmonary arteries did not differ between patients with severe COPD with emphysema and non-smoking control subjects, whereas patients with mild-moderate COPD showed an increased expression of VEGF [170]. Patients with chronic bronchitis phenotype COPD had increased levels of VEGF in sputum in contrast to COPD patients with more emphysema who showed lower levels of VEGF [171]. Patients with acute exacerbations had higher levels of VEGF in the circulation compared to patients with stable COPD and healthy individuals [172]. Increased VEGF expression is associated with bronchial angiogenesis that correlated inversely with lung function in patients with COPD [173, 174]. In contrast, a decreased expression of VEGFR-2 in parenchymal regions in patients with severe COPD correlated with increased endothelial cell death [175]. Inhibition of VEGFR-2 in an animal model resulted in emphysematous lung structure and cell apoptosis [176].VEGF may act both as a promoter of endothelial cell function and a negative regulator of vascular smooth muscle cells and vessel maturation in combination with platelet derived growth factor [177], highlighting the complex role of VEGF in vascular remodelling and its capacity to play different roles depending on disease progression and disease severity. VEGF has the ability to bind to multiple proteins and proteoglycans present in the ECM $[178,179]$. The proteoglycan biglycan is important for migration of cells [180] and may up-regulate VEGF expression [181]. Endothelial cells that form vasculature play an important role in providing nutrients and oxygen to the tumour.

We have previously reported an increase in vessels in general, and VEGF and TGF- $\beta 1$ positive vessels, in particular, in the reticular basement membrane ( $\mathrm{Rbm})$ of smokers and patients with COPD, they were also seen encroaching into the epithelium [182-186]. It is quite possible that these two growth factors actively promote neoangiogenesis of both the Rbm and the epithelium itself, supporting formation of a pro-cancer stroma with associated active EMT [183, 187]. In a separate study, we also reported effects of inhaled fluticasone propionate on vascular remodelling in patients with COPD [187]. In that study, we observed that lamina propria vascularity returned to normal after six months of corticosteroid treatment but that Rbm vessels 
did not decrease significantly. This suggests that six months of corticosteroid therapy may be inadequate for complete depletion of Rbm vessels, and angiogenic sustainability might be the reason for continued cancer growth in both smokers and patients with COPD [188]. We believe these are important clinical observations, which warrant further investigation.

In NSCLC the degree of tumour associated angiogenesis correlates with disease progression and predicts unfavourable outcomes. High vascularity at tumour periphery has been correlated with tumour progression [189]. Perlecan is a major ECM protein located in pulmonary vessels essential for the structure of vascular basement membranes $[178,150]$ and a crucial co-factor for VEGF binding and storage [178]. A study on endothelial cell function showed that interaction between perlecan and VEGF-A promotes VEGFR-2 signalling [190]. Downregulation of perlecan caused reduced angiogenesis in an animal model [191]. Interestingly, perlecan and biglycan synthesis are reduced in fibroblasts from patients with severe COPD [150]. Furthermore, endothelial-derived angiocrine signals were shown to induce regenerative lung alveolarization. Activation of VEGF2 and fibroblast growth factor receptor-1 (FGFR1) in pulmonary capillary endothelial cells induced MMP14 expression that unmasked epidermal growth factor (EGF) receptor ligands to enhance alveologenesis [192]. Perlecan, from endothelial cells, blocked proliferation and invasiveness of lung cancer by acting in a paracrine way to impact pro-inflammatory pathways [193].

Cyclooxygenase-2 (COX-2) is expressed in many tumours, especially adenocarcinoma, and is associated with carcinogenesis and tumour resistance to anti-cancer drugs. COX-2 and prostaglandins (PGs) may play a role in the pathogenesis of lung cancer via effects on angiogenesis, cell proliferation and apoptosis [194]. EGF-induced angiogenesis via the COX2 pathway involves p38 and JNK kinase activation pathways in endothelial cells [195]. COX2 is increased in the distal lung of patients with COPD and also in the sputum of smokers together with MMP-2, which correlated with severity of airflow limitation in patients with stable COPD [196]. COX-2 is also constitutively expressed in different lung cancers including NSCLC [194, 197]. COX-2 via mPGES-1 and PGE 2 receptor EP1 promote cancer growth in a chronic inflammatory environment [198]. Activation of PPAR-receptors by nicotine also induces expression of PGE2 receptor $\mathrm{EP}_{4}$ through $\mathrm{PI} 3-\mathrm{K}$ signals and increased human lung carcinoma cell proliferation in NSCLC [199]. Interestingly, matrix stiffening and fibrosis appear to be linked through COX-2 suppression and reduced $\mathrm{PGE}_{2}$ levels in an autocrine feedback loop [200]. Preclinical and clinical studies have shown that COX-2 inhibitor has some 
efficacy in treatment of NSCLC [201], however further studies are warranted.

\subsection{Genetic predisposition}

A role for familial or genetic susceptibility has been suggested in both COPD and lung cancer. Genome-wide association studies (GWASs) have identified the same risk loci on chromosome 15q that map to CHRNA3 and CHRNA5 - both of which are nicotinic acetyl-choline receptors associated with nicotine dependence and cigarette smoke consumption [202, 203]. The linkage of COPD, lung cancer and peripheral vascular disease, with these genes, points out their possible role as surrogates for tobacco exposure [202]. Single nucleotide polymorphisms of other genes such as FAM13A (at 4q24) that encode for a RhoGTPase-activating protein binding domain have been associated with both COPD and lung cancer [203]. Although their functional contribution to lung cancer and/or COPD remains yet to be elucidated, the involvement of Rho GTPases in the pulmonary endothelial barrier in lung suggests a potential mode of involvement for FAM13A [204]. Direct effects of nicotine have also been reported on endothelial and fibroblast cell populations. In a Swedish study, authors reported that pure nicotine has the potential to alter gene expression, cellular morphology and cell growth of normal human endothelial and fibroblast cells [205]. They suggested that it would potentially promote tumorigenesis and various diseases in cigarette smokers [205]. Nicotine has also been suggested to induce EMT in human airway epithelial cells via the Wnt/ $\beta$-catenin signalling pathway and thereby to increase the risk of lung cancer [206].

\subsection{Epigenetics in lung cancer and COPD}

Besides genetic susceptibility, epigenetic factors such as DNA methylation and covalent histone modifications have been reported to be important in developing COPD and lung cancer. A common methylation link between COPD and lung cancer is CDKN2A which encodes for tumour suppressors p16 (INK4A) and p14 (ARF) [202], an observation consistent with both COPD and lung cancer being viewed as diseases of ageing [207]. Similarly, DNA methylation of the genes CCDC37 and MAP1B was observed in patients with COPD and lung cancer, with the greatest degree of methylation observed in patients with both diseases[207]. In cancer patients with COPD [208], immune genes expressed by either tumour cells or by tumourinfiltrating immune cells were highly methylated as compared to those from patients without COPD [209]. Thus, COPD may epigenetically alter the immune repertoire. 


\subsection{Epithelial-Mesenchymal Transition (EMT)}

Epithelial-mesenchymal transition is a biological process by which epithelial cells lose cellcell adhesion, gain mesenchymal traits of migration and invasion and produce components of extracellular matrix. EMT is a manifestation of airway basal reprogramming in smokers and patients with COPD [210]. EMT need not be a binary process, rather cells can display a spectrum of phenotypes ranging from fully epithelial to fully mesenchymal [211-213]. Hallmarks of EMT have been observed in airways of patients with COPD and smokers, and NSCLC cells can attain either partial EMT - i.e. a hybrid epithelial/mesenchymal (E/M) phenotype - or a complete EMT phenotype [213]. Thus, EMT has been proposed as a potential link between COPD and lung cancer [104].

We have previously reported that EMT is an active process in both small and large airways of patients with COPD [214-219]. EMT associated with organ fibrosis (termed Type-2 EMT) is deprived of angiogenesis. When EMT leads to the formation of pro-cancer stroma, it is termed Type-3 EMT, and is strongly associated with neo-angiogenesis [220, 104, 221]. We have shown that Type-2 EMT is active in small airways, leading to small airway fibrosis/obliteration and Type-3 EMT is active in large airways, where cancer formation (especially SqCC) is quite common, [222, 223]. We also reported that inhaled fluticasone propionate has the potential to ameliorate airway EMT in COPD patients, suggesting EMT as a novel therapeutic target in this condition [183, 224, 225]. EMT may be the mechanism through which inhaled corticosteroids could provide protection against lung cancer in COPD. Statins might have similar effects but further studies are needed to explore their effect [188]. In a cigarette smoke exposed mouse model of COPD, we recently reported that apoptosis signal-regulating kinase 1 (ASK1) inhibition reduced migration of airway smooth muscle cells [226]. These could have implications for EMT as well, as cell migration is one of key hallmarks of epithelial plasticity.

EMT in COPD may be activated by interactions among epithelial cells and fibroblasts [227], reminiscent of non-cell autonomous regulation of EMT in lung cancer [228]. A recent report showed that the acute effects of cigarette smoke and associated infection, together play an important role in driving complete EMT; thus an extra insult, such as an infection can further exaggerate EMT [76] leading to chronically remodelled airways as observed in COPD [229]. SLUG and ZEB1 - transcription factors often associated with a partial EMT[227, 230] - were activated in COPD bronchial epithelial cells, potentially enabling cell survival [231]. We also 
recently reported increased expressions of $\beta$-catenin, Twist and Snail in airways of smokers with and without COPD [219]. These transcriptional regulators of EMT correlated with markers of EMT and were associated with decreased lung function in both smokers and patients with COPD [219]. A partial EMT phenotype can be maintained by adenosine receptor A2BAR that can activate both EMT-inducing (ERK/MAPK) and EMT-inhibiting (cAMP/PKA) pathways[232], similar to the transcription factor NP63 $\alpha$ that can both activate and inhibit ZEB1[233, 234]. Intriguingly, a hybrid E/M phenotype has been identified to possess enriched stem-like abilities as well as resistance to the epidermal growth factor receptor inhibitor erlotinib [235]. The emerging notion about the highly aggressive behaviour of a hybrid E/M phenotype in cancer [236, 237] [238] argues for its potential role in driving COPD, in addition to that of complete EMT.

\subsection{Endothelial-to-mesenchymal transition (EndoMT)}

Similar to epithelial plasticity in EMT, endothelial cells can also lose markers such as vascular endothelial cadherin (VE-cadherin), can attain a motile phenotype and can express fibroblast associated markers such as vimentin, type I collagen, and $\alpha$-smooth muscle actin (SMA) [239]. EndoMT is a critical process during embryogenesis, playing an important role in embryonic cardiac development [240]. However, when challenged by persistent damage and inflammation during pathological conditions, EndoMT is initiated and can contribute to organ fibrosis [241] as well as to cancer promotion [242-244, 241, 245]. As with EMT, EndoMT can also be a nonbinary process, with cells apparently co-expressing both endothelial and mesenchymal markers, suggesting a dual role in disease manifestation [246]. EndoMT, like EMT, may be active in both COPD [247] [248] and lung cancer [249, 250]. In cancer, it is suggested that activated myofibroblasts and cancer-associated fibroblasts produced by EndoMT can facilitate tumour growth and cancer progression. This fits with the underlying cancer pathology wherein tumours are heavily associated with increased angiogenesis, thus, it is possible that endothelial cells are contributing to the pool of CAFs [242, 251, 245]. EndoMT can also initiate the formation of pro-cancer stroma quite similar to Type-3 EMT, with the potential to both initiate cancer and help the tumour to thrive [245].

We and others have reported vascular remodelling in COPD, notably structural changes involving intimal and medial thickening, leading to reduction of lumen diameter and muscularization of arterioles [252]. The other changes involve hypo-vascular lamina propria and hyper-vascular Rbm in large airways of smokers and patients with COPD [253-255, 186, 
256]. Both loss of vessels and vascular remodelling give rise to pulmonary hypertension in COPD [252, 257]. Interestingly, these vascular remodelling changes are also observed in early COPD and in current smokers with normal lung function [252, 258, 168, 253-255, 186]. Increased expression of fibroblast specific protein-1 (FSP-1) has been reported in arteries and small vessels [258]. Abnormal deposition of mesenchymal like cells has been considered as a key pathological feature of arterial remodelling, possibly through endothelium as source of these cells through EndoMT [259]. These cells lead to increased production of ECM proteins, with deposition of collagen and elastin proteins contributing to narrowing of the arterial lumen and the development of pulmonary hypertension. But the origin of these smooth muscle like cells and the underlying mechanisms involved in vascular remodelling are poorly understood [259].

EndoMT has been suggested to be involved in angiogenesis, where, during angiogenic sprouting, endothelial cells may compromise their basement membrane and migrate together as a 'train' of cells, indicating a partial EndoMT phenotype [246]. Similar collective migration has been observed in cells that are maintained in a partial EMT phenotype by molecular brakes such as OVOL2 or GRHL2 that can prevent a complete EMT [260-262][26-28]. 'Phenotypic stability factors' for a partial EndoMT state remain to be identified. Computational approaches to calculate the rates and trajectories of EndoMT may be valuable in better characterizing the dynamics and phenotypic spectrum of EndoMT [263]. Recent studies have highlighted that 'molecular EMT' and 'morphological EMT' does not need to always occur simultaneously, that is, cells expressing markers of EMT need not always migrate/invade, and cells that can invade/migrate need not show molecular markers of EMT [264, 265]. Similar criteria can be used to distinguish between 'molecular EndoMT' and 'morphological EndoMT' as well. Thus, further investigations into the functional and morphological aspects of EndoMT should yield greater insights into the contribution of EndoMT in COPD and cancer progression.

\section{Insights from mouse models of COPD}

Animal models of cigarette smoke (CS)-induced disease using guinea pigs, rats and mice have been developed [266, 267]. Mice are the most popular because of cost, ease of housing, and the availability of a plethora of molecular and immunological reagents and genetically modified strains [267-269]. Mouse models can be used to assess the impact of short-term CS exposure ( 1 day to 4 weeks) or the mechanisms involved in the development of COPD (up to 
6 months). Many of the characteristic features of human COPD, such as chronic lung inflammation, pulmonary hypertension, airway remodelling, emphysema, and impaired lung function, can be generated in CS exposed mice [270-273, 267-269, 274-279]. The effects of CS also predispose to EMT that contributes to the progression of lung cancer $[222,280]$.

Current treatments for COPD such as corticosteroids and bronchodilators are ineffective at inhibiting chronic inflammation, and do not reverse pathology. Thus, it is clear that there is an urgent need to develop new therapies to prevent the initiation and progression of COPD, and an effective option is using animal models that accurately reflect the physiopathology of the disease. Indeed, many potential future COPD therapeutics currently in clinical development, such as inhibitors of inflammatory mediators, oxidative stress, kinases, phosphodiesterases (PDE) and proteinases were originally identified in studies using animal models.

Various inhibitors of inflammatory mediators are being developed and tested for the treatment of COPD. Inhibitors of TRAIL, leukotriene B4 (LTB4), TNF- $\alpha$, IL-1, IL-8, and epidermal growth factor have shown strong beneficial effects when used in animal models, however translation into the clinic has been slow [281]. Studies exposing TNF- $\alpha$ receptor deficient mice to $\mathrm{CS}$ resulted in reduced inflammatory cells in lavage fluid and attenuated alveolar enlargement compared to wild-type mice [282]. These findings were supported by another knockout mouse study where both TNF- $\alpha$ receptors were shown to contribute to the pathogenesis of murine COPD, with TNF- $\alpha$ receptor- 2 being the most active in the development of systemic weight loss, inflammation and emphysema [283]. However, as occurred with asthma, where mouse studies were not interpreted properly or transferred effectively into clinical studies, it is likely that selected groups or phenotypes of patients may respond better to specific treatments [284].

Anti-oxidants, particularly those that target specific processes in COPD have shown some promise. Resveratrol and the antioxidant enzyme Gpx-1 have been shown to protect against lung inflammation and CS-induced emphysema in mice, and a Gpx mimetic also reduced lung inflammation when administered both prophylactically and therapeutically [285, 286]. Resveratrol is a plant originated polyphenol that suppresses lung inflammation through upregulating MyD88s which is a negative regulator of inflammation [286].

Studies of animal models of CS-induced airway inflammation support the potential therapeutic 
use of kinase inhibitors, such as those that inhibit p38 mitogen-activated protein kinase (MAPK) and phosphatidylinositol 3-kinase (PI3K), in COPD [287]. MAPKs plays key roles in chronic inflammation [288]. The p38 MAPK pathway is activated by cellular stress and regulates the expression of various inflammatory cytokines and remodeling factors including IL-8, TNF- $\alpha$ and MMPs [289]. PI3Ks play roles in controlling a several intracellular signaling pathways in asthma and COPD [290, 274]. Recent studies suggest that numerous components of the PI3K pathway contribute to the expression and activation of inflammatory mediators, inflammatory cell recruitment, immune cell function and airway remodelling as well as corticosteroid insensitivity in chronic inflammatory respiratory diseases such as asthma [291, 290, 274]. We recently discovered that PI3K also plays a pivotal role in the pathogenesis of COPD. Its activity increases and is utilised by influenza virus during infections to suppress anti-viral responses $[292,274]$.

The PDE4 inhibitor roflumilast, a licensed treatment for severe COPD, was originally identified as a potential therapeutic in acute and chronic murine models of CS-exposure [293]. PDE4 degrades the anti-inflammatory cyclic adenosine monophosphate and its inhibition in mice has been shown to have protective effects including reversing the loss of lung desmosine, (a breakdown product of elastin), reducing neutrophil and macrophage influx, increasing the anti-inflammatory cytokine IL-10, and improving emphysema [293]. Other murine studies showed that another PDE4 inhibitor - rolipram, had little effect on airway inflammation and remodeling or emphysema whereas a semicardazide-sensitive mono-amine oxidase inhibitor $\operatorname{did}[279]$.

Serine-, metallo- and cysteine proteinases are the primary proteinases implicated in the development of COPD [294]. In studies aimed at preventing the destruction of alveolar walls by proteolysis, and ultimately the development of emphysema, inhibitors of various proteinases have been trialed in animal models with varying levels of success. Emerging studies are also using mouse models to elucidate the roles of other new areas such as inflammasomes, microbiomes and the gut lung axis [295-299]. Collectively, the use of murine models of COPD and infective exacerbations is valuable in furthering our understanding of the pathogenic aspects of the disease with the aim of identifying novel therapeutic targets and developing and testing new therapies [300]. The inherent heterogeneity of the disease can also be reproduced and studied in animal models using different combinations or doses of induction agents. 


\section{Insights from mouse models of lung cancer}

Numerous different mouse models have been developed to study the etiology, transformation, invasion and metastasis of lung cancer. These models have been used to elucidate the mechanisms of cancer initiation, progression and metastasis, and to discover biomarkers, as well as in testing preventives and treatments. Different types of mouse models of lung cancer have been developed, with the vast majority using immunodeficient or genetically modified mice.

Xenograft models are induced by injecting human lung cancer cells subcutaneously, orthotopically or systemically into immunocompromised mice. These models are mainly used to assess the efficacy of drugs before proceeding to clinical trials. Cell lines commonly used in xenograft mouse models are HCC4006, HCC827, H1975 and A549 for adenocarcinomas [301303]; NCI-H1299 for carcinomas [304]; NCI-H460 for large cell carcinomas [305]; and NCI$\mathrm{H} 226$ for SqCC [306]. Another type is termed the patient derived xenograft (PDX) mouse model where surgically removed human primary tumour tissues are grafted into mice subcutaneously or orthotopically. These models are used to develop and test personalised therapies [307]. Although xenograft models are relatively poor in predicting clinical efficacy of drugs, these models have been successfully used for developing personalised therapy [308]. Hodgkinson and colleagues demonstrated that circulating tumour cells (CTCs) molecular analysis via serial blood sampling could facilitate delivery of personalized medicine for SCLC. CTC-derived explants are readily passaged, and these unique mouse models provide tractable systems for therapy testing and understanding drug resistance mechanisms. [309]. Apart from this, xenograft models also showed accuracy in testing the efficacy of a number of drugs such as gefitinib, erlotinib and crizotinib, which showed similar results in clinical trials as seen in mouse models [310-315].

Transgenic mouse models are generated by microinjecting modified DNA into zygotes, and are used to explore the functional activity of the gene of interest- particularly their impact on the initiation, progression and metastasis of lung cancer [316]. A lung specific promoter is added to the coding region of the target gene in modified DNA to enable its expression only in the lung, and not in other organs or tissues [316]. A transgenic mouse model was developed to test the dependency of EGFR signalling in tumour development and progression. This model also showed that inhibiting EGFR through small molecular inhibitors (erlotinib or HKI-272) 
and humanized anti-hEGFR antibody (cetuximab) was effective in inducing tumour regression [317].

Syngeneic mouse models are generated by injecting immunologically compatible cancer cells into immunocompetent mice. The use of these models in the study of lung cancer is rare and the only mouse model developed so far is the Lewis lung carcinoma model [318]. This model is valuable for investigating the tumour microenvironment and exploring the immune and toxicological responses of potential drugs. Spontaneous models are induced using oral, intraperitoneal or topical application of carcinogens to genetically susceptible but wild-type mouse strains like A/J and SWR. Carcinogens used are cigarette smoke, 4-methylnitrosamino3-pyridyl-1-butanone (NNK), benzo(a)pyrene for adenocarcinomas [319, 320], and N-nitrosotris-chloroethyl urea (NTCU) for SqCC [321]. Small cell lung cancer is induced through inactivation of both $\mathrm{Rb}$ and p53 genes. These models are valuable for exploring carcinogenesis, disease pathology, biomarker discovery, tumour microenvironment and roles of immune cells in cancer initiation development and progression, immune responses and the efficacy and toxicology of drug treatment [322].

Carcinogens such as cigarette smoke and NNK, can be combined to induce adenomas and after many months, adenocarcinomas. Published models are long term at 5-9 months [323, 320, 324]. Initially, hyperplastic foci are seen in the bronchioles and alveoli that develop as adenomas and then progress to adenocarcinomas [325]. It is often difficult to distinguish adenomas, premalignant adenomas and malignant adenocarcinomas. Adenocarcinomas are mostly distinguished from other tumours based on characteristics such as the presence of large pleiomorphic cells with vesicular nuclei, prominent nucleoli, undifferentiated cytoplasm and high mitotic index [326]. Morphologically, they have both solid and papillary characteristics [327]. Tumours that develop in mice have low vascularization and metastatic potential [323]. Club cells (originally known as Clara cells), alveolar type II cells, multipotent stem cells or derivative lineages of these cells are usually the cells of origin of tumours $[327,328]$. The origin of papillary tumours is unclear, however, solid tumours usually originate from alveolar type II cells [327]. The histopathological and molecular characteristics of spontaneous mouse lung adenocarcinoma models are similar to the tumours that develop in humans [326].

Squamous cell carcinoma (SqCC), mouse models can be induced using N-nitroso-trischloroethylurea (NTCU) administration and initially show premalignant lesions which 
progress to frank lung SqCC similar to those that develop in humans [329]. SCLCs in mice are histologically similar to those seen in humans with a similar pattern of metastatic disease [330]. Neuroendocrine cells are believed to be the origin of SCLC [331].

Further characterisation of lung cancer mouse models and the development of novel models that accurately recapitulate the histological, immunological and molecular characteristics of human tumours are needed to advance our understanding of lung cancer and to discover more effective early diagnostics and treatment.

\section{Conclusions}

Currently, there is a lack of strong evidence to suggest that medical management for COPD should be modified in patients with concomitant lung cancer. Given both COPD and lung cancer are heterogeneous conditions, individualised treatment strategies are needed for patient management. Optimisation of care for patients with COPD prior to, during and after definitive treatment for lung cancer should be part of the multidisciplinary management of patients with these dual pathologies. The use of long-acting bronchodilators and pulmonary rehabilitation is the mainstay management for these patients. Addition of inhaled corticosteroids is appropriate for patients with moderate-to-severe COPD and recurrent exacerbations. Inhaled corticosteroids may have the potential to ameliorate EMT in patients with COPD, thus potentially protecting against the development of lung cancer. However, at this stage, there is no prospective data linking corticosteroid therapy to cancer protection, and ICS continue to be reserved for those with more severe COPD and either or both of poorly controlled symptoms and exacerbations. There is an urgent need for the development of new therapeutics, which could be given in early COPD, given that the incidence of lung cancer is even higher in patients with mild-moderate COPD (GOLD 1 and 2) than in those with more severe disease [332]. Therapeutic options available for patients with lung cancer and concomitant COPD have improved with advances in radiotherapy such as IMRT and SABR, as well as systemic therapies such as TKI and immunotherapy. However, pneumonitis secondary to radiotherapy or systemic therapies is a potential significant side effect in patients with pre-existing lung disease. At present, it is unknown whether COPD or its therapies may impact on the development or clinical course of therapy-related lung toxicity. Well-controlled clinical trials are needed to explore the efficacy of various strategies for reducing lung cancer risk in patients with COPD and improving clinical outcomes for patients with both diseases. There is a need 
for the development of pre-clinical animal models, which more faithfully represent human disease. With increasing understanding of the molecular pathogenesis underlying both lung cancer and COPD, new strategies using molecularly targeted therapies may be developed in future for prevention of lung cancer and treatment of COPD in this population.

\section{Acknowledgments}

SSS is supported by Clifford Craig Foundation Launceston, Thoracic Society of Australia \& New Zealand (TSANZ) and Boehringer Ingelheim COPD Research Award, PMH is supported by an NHMRC Principal Research Fellowship and a Brawn Fellowship, Faculty of Health, University of Newcastle.VC is supported by Cancer Council WA postdoctoral fellowship. MKJ is supported by a training fellowship from the Gulf Coast Consortia, on the Computational

Cancer Biology Training Program. PS is supported by Rebecca L. Cooper Medical Research Foundation, Australia and Chancellors Fellowship Programme, University of Technology Sydney (UTS).

\section{Compliance with Ethical Standards}

\section{Conflict of interest}

The following authors declare no conflict of interest: Mathew Suji Eapen, Anna Karin LarssonCallerfelt, Mohit K. Jolly, Stephen Myers, Pawan Sharma, Bernadette Jones, Md Atiqur Rahman, James Markos, Collin Chia, Josie Larby, Greg Haug, Ashutosh Hardikar, Heinrich C. Weber, George Mabeza, Vinicius Cavalheri.

Sukhwinder Singh Sohal: Reports grants from Thoracic Society of Australia and New Zealand (TSANZ), Boehringer Ingelheim and Clifford Craig Foundation.

Philip M. Hansbro: There are no conflicts related to this manuscript aside from it concerns mouse models of lung cancer and COPD that we regularly use.

Yet H. Khor: Reports grants from National Health and Medical Research Council, Boehringer Ingelheim and non-financial support from Air Liquide, outside the submitted work; honorarium from Boehringer Ingelheim, Roche and Astra Zeneca, outside the submitted work.

Christine F. McDonald: I have received speakers fees / participated in advisory boards in the past: GSK, Pfizer, Novartis; have donated speaker fees from Menarini to my hospital.

\section{Funding}

The preparation of this review was not supported by any external funding. 
Table 1: Observational studies of inhaled corticosteroids (ICS), statins and risk of lung cancers in patients with COPD

\begin{tabular}{|c|c|c|c|c|}
\hline Reference & Design (duration) & $\begin{array}{l}\text { Number of } \\
\text { participants }\end{array}$ & Type of drug & $\begin{array}{l}\text { Hazard ratio } \\
{[95 \% \mathrm{CI}]}\end{array}$ \\
\hline $\begin{array}{l}\text { Parimon } \\
2007 \text { [23] }\end{array}$ & $\begin{array}{l}\text { Retrospective cohort } \\
\text { study (median } 3.8 \\
\text { years) }\end{array}$ & $\begin{array}{l}\text { ICS }=517 \\
\text { No ICS = 9957 }\end{array}$ & $\begin{array}{l}\text { Triamcinolone, } \\
\text { beclomethasone, } \\
\text { flunisolide and } \\
\text { fluticasone }\end{array}$ & $\begin{array}{l}\text { Adjusted: } \\
\mathrm{ICS}<1200 \mu \mathrm{g}=1.3(0.67- \\
1.90) \\
\mathrm{ICS} \geq 1200 \mu \mathrm{g}=0.39(0.16- \\
0.96)\end{array}$ \\
\hline $\begin{array}{l}\text { Kiri } 2009 \\
{[24]}\end{array}$ & $\begin{array}{l}\text { Retrospective nested } \\
\text { case-control study } \\
\text { (1989-2003 to June } \\
2005)\end{array}$ & $\begin{array}{l}\text { ICS }=127 \\
\text { No ICS }=1470\end{array}$ & Any ICS & $\begin{array}{l}\text { Overall }=0.64(0.42-0.98) \\
1-2 \text { prescriptions/year }=0.88 \\
(0.51-1.52) \\
3+\text { prescriptions/year } \\
=0.51(0.30-0.84)\end{array}$ \\
\hline $\begin{array}{l}\text { Liu } 2017 \\
{[25]}\end{array}$ & $\begin{array}{l}\text { Retrospective cohort } \\
\text { study (median } 9.8 \\
\text { years) }\end{array}$ & $\begin{array}{l}\text { ICS = 1290 } \\
\text { No ICS = } \\
12396\end{array}$ & $\begin{array}{l}\text { Fluticasone and } \\
\text { budesonide }\end{array}$ & $\begin{array}{l}\text { Overall }=0.70(0.46-1.09) \\
\text { Cumulative ICS dose }> \\
39.48 \mathrm{mg}=0.45(0.21-0.96)\end{array}$ \\
\hline $\begin{array}{l}\text { Liu } 2016 \\
{[30]}\end{array}$ & $\begin{array}{l}\text { Retrospective cohort } \\
\text { study (between } \\
\text { January 1, } 2001 \text { and } \\
\text { December } 31,2012\end{array}$ & $\begin{array}{l}\text { Simvastatin = } \\
3418 \\
\text { Lovastatin = } \\
2109 \\
\text { Atorvastatin = } \\
5484 \\
\text { Fluvastatin = } \\
1510 \\
\text { Pravastatin = } \\
1501 \\
\text { Rosuvastatin = } \\
2741\end{array}$ & Statins & $\begin{array}{l}\text { Overall lung cancer risk in the } \\
\text { statin users was lower than that } \\
\text { in the statin nonusers (adjusted } \\
\text { hazard ratio [aHR] = 0.37) } \\
\text { Of the individual statins, } \\
\text { lovastatin and fluvastatin did } \\
\text { not reduce lung cancer risk } \\
\text { significantly } \\
\text { Lung cancer risk in patients } \\
\text { using rosuvastatin, simvastatin, } \\
\text { atorvastatin, and pravastatin } \\
\text { was significantly lower than } \\
\text { that in statin nonusers (aHRs = } \\
0.41,0.44,0.52 \text {, and } 0.58, \\
\text { respectively) }\end{array}$ \\
\hline
\end{tabular}

ICS inhaled corticosteroids; COPD chronic obstructive pulmonary disease 
Figure 1: Showing shared mechanisms between COPD and lung cancer. ROS reactive oxygen species; RNS reactive nitrogen species; EMT epithelial mesenchymal transition; EndoMT; endothelial to mesenchymal transition; $E C M$ extracellular matrix; $M M P S$ matrix metalloproteinases. 


\section{References}

1. Quaderi SA, Hurst JR. The unmet global burden of COPD. Global health, epidemiology and genomics. 2018;3:e4. doi:10.1017/gheg.2018.1.

2. Brenner D, McLaughlin J, Hung R. Previous lung diseases and lung cancer risk: a systemic review and meta-analysis. PLoS One. 2011;6:e17479.

3. Tammemagi C, Neslund-Dudas C, Simoff M, Kvale P. Impact of comorbidity on lung cancer survival. Int J Cancer. 2003;103:792-02.

4. López-Encuentra A, Astudillo J, Cerezal J, Gonzalez-Aragoneses F, Novoa N, SánchezPalencia A et al. Prognostic value of chronic obstructive pulmonary disease in 2994 cases of lung cancer. Eur J Cardiothorac Surg. 2005;27:8-13.

5. Kiri V, Soriano J, Visick G, Fabbri L. Recent trends in lung cancer and its association with COPD: an analysis using the UK GP Research Database. Prim Care Respir J. 2010;19:57-61.

6. Didkowska J, Wojciechowska U, Mańczuk M, Łobaszewski J. Lung cancer epidemiology: contemporary and future challenges worldwide. Annals of Translational Medicine. 2016;4(8):150. doi:10.21037/atm.2016.03.11.

7. Wong MCS, Lao XQ, Ho K-F, Goggins WB, Tse SLA. Incidence and mortality of lung cancer: global trends and association with socioeconomic status. Scientific Reports. 2017;7(1):14300. doi:10.1038/s41598-017-14513-7.

8. Islami F, Torre LA, Jemal A. Global trends of lung cancer mortality and smoking prevalence. Translational Lung Cancer Research. 2015;4(4):327-38. doi:10.3978/j.issn.22186751.2015.08.04.

9. Oberg M, Jaakkola MS, Woodward A, Peruga A, Pruss-Ustun A. Worldwide burden of disease from exposure to second-hand smoke: a retrospective analysis of data from 192 countries. Lancet (London, England). 2011;377(9760):139-46. doi:10.1016/s01406736(10)61388-8.

10. Hamra GB, Guha N, Cohen A, Laden F, Raaschou-Nielsen O, Samet JM et al. Outdoor Particulate Matter Exposure and Lung Cancer: A Systematic Review and Meta-Analysis. Environmental Health Perspectives. 2014;122(9):906-11. doi:10.1289/ehp/1408092.

11. AIHW. Cancer in Australia 2017. 2017.

12. Inamura K. Lung Cancer: Understanding Its Molecular Pathology and the 2015 WHO Classification. Frontiers in Oncology. 2017;7:193. doi:10.3389/fonc.2017.00193.

13. Travis WD, Brambilla E, Nicholson AG, Yatabe Y, Austin JHM, Beasley MB et al. The 2015 World Health Organization Classification of Lung Tumors. Journal of Thoracic Oncology.10(9):1243-60. doi:10.1097/JTO.0000000000000630.

14. Derman BA, Mileham KF, Bonomi PD, Batus M, Fidler MJ. Treatment of advanced squamous cell carcinoma of the lung: a review. Translational Lung Cancer Research. 2015;4(5):524-32. doi:10.3978/j.issn.2218-6751.2015.06.07.

15. Hanna JM, Onaitis MW. Cell of origin of lung cancer. Journal of Carcinogenesis. 2013;12:6. doi:10.4103/1477-3163.109033.

16. Weissferdt A. Large cell carcinoma of lung: On the verge of extinction? Seminars in Diagnostic Pathology. 2014;31(4):278-88. doi:https://doi.org/10.1053/j.semdp.2014.06.005.

17. Leary AR. Lung cancer. [electronic resource] : a multidisciplinary approach. Chichester, West Sussex, UK : Wiley-Blackwell, 2011.; 2011.

18. Shepherd FA, Crowley J, Van Houtte P, Postmus PE, Carney D, Chansky K et al. The International Association for the Study of Lung Cancer Lung Cancer Staging Project: Proposals Regarding the Clinical Staging of Small Cell Lung Cancer in the Forthcoming (Seventh) Edition of the Tumor, Node, Metastasis Classification for Lung Cancer. Journal of Thoracic Oncology.2(12):1067-77. doi:10.1097/JTO.0b013e31815bdc0d. 
19. World Health Organization International Histological Classification of Tumours: Histological Typing of Endocrine Tumours: Second Edition. Clinical Endocrinology. 2000;53(2):259-. doi:doi:10.1046/j.1365-2265.2000.01073.x.

20. Anthonisen N, Skeans M, Wise R, Manfreda J, Kanner R, Connett J. The effects of a smoking cessation intervention on 14.5-year mortality: a randomized clinical trial. Ann Intern Med. 2005;142:299-301.

21. Godtfredsen N, Prescott E, Osler M. Effect of smoking reduction on lung cancer risk. JAMA. 2005;294:1505-10.

22. Dragnev K, Stover D, Dmitrovsky E. Lung cancer prevention: the guidelines. Chest. 2003;123:60S-71S.

23. Parimon T, Chien J, Bryson C, McDonell M, Udris E, Au D. Inhaled corticosteroids and risk of lung cancer among patients with chronic obstructive pulmonary disease. American journal of respiratory and critical care medicine. 2007;175:712-9.

24. Kiri V, Fabbri L, Davis K, Soriano J. Inhaled corticosteroids and risk of lung cancer among COPD patients who quit smoking. Resp Med. 2009;103:85-90.

25. Liu S, Kuo H, Lin M, Ho S, Tu M, Chen Y et al. Inhaled corticosteroids have a protective effect against lung cancer in female patients with chronic obstructive pulmonary disease: a nationwide population-based cohort study. Ontotarget. 2017;8:29711-21.

26. Sin D, Wu L, Anderson J, Anthonisen N, Buist A, Burge P et al. Inhaled corticosteroids and mortality in chronic obstructive pulmonary disease. Thorax. 2005;60:992-7.

27. Lam S, leRiche J, McWilliams A, Macaulay C, Dyachkova Y, Szabo E et al. A randomized phase IIb trial of pulmicort turbuhaler (budesonide) in people with dysplasia of the bronchial epithelium. Clin Cancer Res. 2004;10:6502-11.

28. van den Berg R, Teertstra H, van Zandwijk N, van Tinteren H, Visser C, Pasic A et al. CT detected indeterminate pulmonary nodules in a chemoprevention trial of fluticasone. Lung Cancer. 2008;60:57-61.

29. Young RP, Hopkins RJ. Effect of statins on cancer in chronic obstructive pulmonary disease. Thorax. 2011;66(4):354-5; author reply 5-6. doi:10.1136/thx.2009.131250.

30. Liu J, Yang T, Hsu Y, Hao W, Kao P, Sung L et al. Statins dose-dependently exert a chemopreventive effect against lung cancer in COPD patients: a population-based cohort study. Ontotarget. 2016;7:59618-29.

31. Myung S, Kim Y, Ju W, Choi H, Bae W. Effects of antioxidant supplements on cancer prevention: meta-analysis of randomized controlled trials. Ann Oncol. 2010;21:166-79.

32. Alpha-Tocopherol BCCPSG. The effect of vitamin E and beta carotene on the incidence of lung cancer and other cancers in male smokers. The New England journal of medicine. 1994;330:1029-35.

33. Omenn G, Goodman G, Thornquist M, Balmes J, Cullen M, Glass A et al. Effects of a combination of beta carotene and vitamin $\mathrm{A}$ on lung cancer and cardiovascular disease. The New England journal of medicine. 1996;334:1150-5.

34. Brasky T, White E, Chen C. Long-Term, Supplemental, One-Carbon Metabolism-Related Vitamin B Use in Relation to Lung Cancer Risk in the Vitamins and Lifestyle (VITAL) Cohort. J Clin Oncol. 2017;35:3440-8.

35. Spruit MA, Singh SJ, Garvey C, ZuWallack R, Nici L, Rochester C et al. An official American Thoracic Society/European Respiratory Society statement: key concepts and advances in pulmonary rehabilitation. American journal of respiratory and critical care medicine. 2013;188(8):e13-e64. doi:10.1164/rccm.201309-1634ST.

36. Jones LW, Eves ND, Haykowsky M, Joy AA, Douglas PS. Cardiorespiratory exercise testing in clinical oncology research: systematic review and practice recommendations. Lancet Oncol. 2008;9(8):757-65. doi:S1470-2045(08)70195-5 [pii] 
10.1016/S1470-2045(08)70195-5.

37. Jones LW, Watson D, Herndon JE, 2nd, Eves ND, Haithcock BE, Loewen G et al. Peak oxygen consumption and long-term all-cause mortality in nonsmall cell lung cancer. Cancer. 2010;116(20):4825-32. doi:10.1002/cncr.25396.

38. Oga T, Nishimura K, Tsukino M, Sato S, Hajiro T. Analysis of the factors related to mortality in chronic obstructive pulmonary disease: role of exercise capacity and health status. American journal of respiratory and critical care medicine. 2003;167(4):544-9. doi:10.1164/rccm.200206-5830C.

39. Singh SJ, Puhan MA, Andrianopoulos V, Hernandes NA, Mitchell KE, Hill CJ et al. An official systematic review of the European Respiratory Society/American Thoracic Society: measurement properties of field walking tests in chronic respiratory disease. The European respiratory journal. 2014;44(6):1447-78. doi:10.1183/09031936.00150414.

40. Irie M, Nakanishi R, Yasuda M, Fujino Y, Hamada K, Hyodo M. Risk factors for shortterm outcomes after thoracoscopic lobectomy for lung cancer. The European respiratory journal. 2016;48(2):495-503. doi:10.1183/13993003.01939-2015.

41. Brunelli A, Kim AW, Berger KI, Addrizzo-Harris DJ. Physiologic evaluation of the patient with lung cancer being considered for resectional surgery: Diagnosis and management of lung cancer, 3rd ed: American College of Chest Physicians evidence-based clinical practice guidelines. Chest. 2013;143(5 Suppl):e166S-90S. doi:10.1378/chest.12-2395

1685249 [pii].

42. From the Global Strategy for the Diagnosis, Management and Prevention of COPD, Global Initiative for Chronic Obstructive Lung Disease (GOLD). 2017. http://goldcopd.org.

43. Cavalheri V, Jenkins S, Cecins N, Gain K, Phillips MJ, Sanders LH et al. Exercise training for people following curative intent treatment for non-small cell lung cancer: a randomized controlled trial. Braz J Phys Ther. 2017;21(1):58-68. doi:10.1016/j.bjpt.2016.12.005.

44. Cavalheri V, Granger C. Preoperative exercise training for patients with non-small cell lung cancer. Cochrane Database Syst Rev. 2017;6:CD012020. doi:10.1002/14651858.CD012020.pub2.

45. Edvardsen E, Skjonsberg OH, Holme I, Nordsletten L, Borchsenius F, Anderssen SA. High-intensity training following lung cancer surgery: a randomised controlled trial. Thorax. 2015;70(3):244-50. doi:10.1136/thoraxjnl-2014-205944.

46. Karenovics W, Licker M, Ellenberger C, Christodoulou M, Diaper J, Bhatia C et al. Shortterm preoperative exercise therapy does not improve long-term outcome after lung cancer surgery: a randomized controlled studydagger. Eur J Cardiothorac Surg. 2017. doi:10.1093/ejcts/ezx030.

47. Alison JA, McKeough ZJ, Johnston K, McNamara RJ, Spencer LM, Jenkins SC et al. Australian and New Zealand Pulmonary Rehabilitation Guidelines. Respirology. 2017;22(4):800-19. doi:10.1111/resp.13025.

48. McCarthy B, Casey D, Devane D, Murphy K, Murphy E, Lacasse Y. Pulmonary rehabilitation for chronic obstructive pulmonary disease. Cochrane Database Syst Rev. 2015;2:CD003793. doi:10.1002/14651858.CD003793.pub3.

49. Puhan MA, Gimeno-Santos E, Cates CJ, Troosters T. Pulmonary rehabilitation following exacerbations of chronic obstructive pulmonary disease. Cochrane Database Syst Rev. 2016;12:CD005305. doi:10.1002/14651858.CD005305.pub4.

50. Cavalheri V, Tahirah F, Nonoyama M, Jenkins S, Hill K. Exercise training for people following lung resection for non-small cell lung cancer - A Cochrane systematic review. Cancer treatment reviews. 2014;40(4):585-94. doi:10.1016/j.ctrv.2013.11.001. 
51. Cavalheri V, Jenkins S, Hill K. Physiotherapy practice patterns for patients undergoing surgery for lung cancer: a survey of hospitals in Australia and New Zealand. Intern Med J. 2013;43(4):394-401. doi:10.1111/j.1445-5994.2012.02928.x.

52. Mujovic N, Mujovic N, Subotic D, Marinkovic M, Milovanovic A, Stojsic J et al. Preoperative pulmonary rehabilitation in patients with non-small cell lung cancer and chronic obstructive pulmonary disease. Arch Med Sci. 2014;10:68-75.

53. Saito H, Hatakeyama K, Konno H, Matsunaga T, Shimada Y, Minamiya Y. Impact of pulmonary rehabilitation on postoperative complications in patients with lung cancer and chronic obstructive pulmonary disease. Thorac Cancer. 2017;8:451-60.

54. Wang JS, Abboud RT, Wang LM. Effect of lung resection on exercise capacity and on carbon monoxide diffusing capacity during exercise. Chest. 2006;129(4):863-72. doi:129/4/863 [pii]

10.1378/chest.129.4.863.

55. Cavalheri V, Jenkins S, Cecins N, Gain K, Phillips M, Sanders LH et al. Impairments after curative intent treatment for non-small cell lung cancer: a comparison with age and gendermatched healthy controls. Respir Med. 2015;109(10):1332-9. doi:10.1016/j.rmed.2015.08.015. 56. Wiskemann J, Hummler S, Diepold C, Keil M, Abel U, Steindorf K et al. POSITIVE study: physical exercise program in non-operable lung cancer patients undergoing palliative treatment. BMC Cancer. 2016;16:499. doi:10.1186/s12885-016-2561-1.

57. Quist M, Langer SW, Rorth M, Christensen KB, Adamsen L. "EXHALE": exercise as a strategy for rehabilitation in advanced stage lung cancer patients: a randomized clinical trial comparing the effects of 12 weeks supervised exercise intervention versus usual care for advanced stage lung cancer patients. BMC Cancer. 2013;13:477. doi:10.1186/1471-2407-13477.

58. Edbrooke L, Aranda S, Granger CL, McDonald CF, Krishnasamy M, Mileshkin L et al. Benefits of home-based multidisciplinary exercise and supportive care in inoperable non-small cell lung cancer - protocol for a phase II randomised controlled trial. BMC Cancer. 2017;17(1):663. doi:10.1186/s12885-017-3651-4.

59. Quist M, Rorth M, Langer S, Jones LW, Laursen JH, Pappot H et al. Safety and feasibility of a combined exercise intervention for inoperable lung cancer patients undergoing chemotherapy: a pilot study. Lung Cancer. 2012;75(2):203-8. doi:10.1016/j.lungcan.2011.07.006.

60. Markos J, Mullan B, Hillman D, Musk A, Antico V, Lovegrove F et al. Preoperative assessment as a predictor and mortality and morbidity after lung resection. Am Rev Respir Dis. 1989;139:902-10.

61. Sekine Y, Behnia M, Fujisawa T. Impact of COPD on pulmonary complications and on long-term survival of patients undergoing surgery for NSCLC. Lung Cancer. 2002;37:95-101. 62. Sekine Y, Kesler K, Behnia M, Brooks-Brunn J, Sekine E, Brown J. COPD may increase the incidence of refractory supraventricular arrhythmias following pulmonary resection for non-small cell lung cancer. Chest. 2001;120:1783-90.

63. Win T, Jackson A, Sharples L, Groves A, Wells F, Ritchie A et al. Relationship between pulmonary function and lung cancer surgical outcomes. The European respiratory journal. 2005;25:594-9.

64. Vogelmeier C, Criner G, Martinez F, Anzueto A, Barnes P, Bourbeau J et al. Global strategy for the diagnosis, management, and prevention of chronic obstructive lung disease 2017 report. GOLD executive summary. American journal of respiratory and critical care medicine. 2017;195:557-82. 
65. Yang I, Brown J, George J, Jenkins S, McDonald C, McDonald V et al. COPD-X Australian and New Zealand guidelines for the diagnosis and management of chronic obstructive pulmonary disease: 2017 update. Med J Aust. 2017;207:436-42.

66. Kobayashi S, Suzuki S, Niikawa H, Sugawara T, Yanai M. Preoperative use of inhaled tiotropium in lung cancer patients with untreated COPD. Respirology. 2009;14:675-9.

67. Bölükbas S, Eberlein M, Eckhoff J, Schirren J. Short-term effects of inhalative tiotropium/formoterol/budesonide versus tiotropium/formoterol in patients with newly diagnosed chronic obstructive pulmonary disease requiring surgery for lung cancer: a prospective randomized trial. Eur J Cardio-thoracic Surgery. 2011;39:995-1000.

68. Nojiri T, Inoue M, Yamamoto K, Maeda H, Takeuchi Y, Nakagiri T et al. Inhaled tiotropium to prevent postoperative cardiopulmonary complications in patients with newly diagnosed chronic obstructive pulmonary disease requiring lung cancer surgery. Surg Today. 2014; 44:285-90.

69. Takegahara K, Usuda J, Inoue T, Ibi T, Sato A. Preoperative management using inhalation therapy for pulmonary complications in lung cancer patients with chronic obstructive pulmonary disease. Gen Thorac Cardiovasc Surg. 2017;65:388-91.

70. Suzuki H, Sekine Y, Yoshida S, Suzuki M, Shibuya K, Takiguchi Y et al. Efficacy of perioperative administration of long-acting bronchodilator on postoperative pulmonary function and quality of life in lung cancer patients with chronic obstructive pulmonary disease. Preliminary results of a randomized control study. Surg Today. 2010;40:923-30.

71. Nojiri T, Maeda H, Takeuchi Y, Funakoshi Y, Maekura R, Yamamoto K et al. Predictive value of preoperative tissue Doppler echocardiographic analysis for postoperative atrial fibrillation after pulmonary resection for lung cancer. J Thorac Cardiovasc Surg. 2010;140:764-48.

72. Yamanashi K, Marumo S, Sumitomo R, Shoji T, Fukui M, Katayama T et al. Long-acting B2-adrenoceptor agonists are not associated with atrial arrhythmias after pulmonary resection. J Cardiothorac Surg. 2017;12:35. doi:10.1186/s13019-017-0606-4.

73. Crim C, Calverley P, Anderson J, Celli B, Ferguson G, Jenkins C et al. Pneumonia risk in COPD patients receiving inhaled corticosteroids alone or in combination: TORCH study results. The European respiratory journal. 2009;34:641-7.

74. Calverley P, Stockley R, Seemungal T, Hagan G, Willits L, Riley J et al. Reported pneumonia in patients with COPD: findings from the INSPIRE study. Chest. 2011;139:50512.

75. Drummond M, Dasenbrook E, Pitz M, Murphy D, Fan E. Inhaled corticosteroids in patients with stable chronic obstructive pulmonary disease: a systematic review and meta-analysis. JAMA. 2008;300:2407-16.

76. Eapen MS, Sohal SS. Understanding novel mechanisms of microbial pathogenesis in chronic lung disease: implications for new therapeutic targets. Clin Sci (Lond). 2018;132(3):375-9. doi:10.1042/cs20171261.

77. Sohal SS. Fluticasone propionate and increased risk of pneumonia in COPD: is it PAFRdependent? Int J Chron Obstruct Pulmon Dis. 2017;12:3425-7. doi:10.2147/copd.S154897.

78. Sohal SS. Inhaled corticosteroids and increased microbial load in COPD: potential role of epithelial adhesion molecules. The European respiratory journal. 2018;51(2). doi:10.1183/13993003.02257-2017.

79. Sohal SS, Eapen MS, Ward C, Walters EH. Airway inflammation and inhaled corticosteroids in COPD. The European respiratory journal. 2017;49(6). doi:10.1183/13993003.00289-2017.

80. Yamanashi K, Marumo S, Shoji T, Fukui T, Sumitomo R, Otake Y et al. The relationship between perioperative administration of inhaled corticosteroid and postoperative respiratory 
complications after pulmonary resection for non-small-cell lung cancer in patients with chronic obstructive pulmonary disease. Gen Thorac Cardiovasc Surg. 2015;63:652-9.

81. Warner MA, Offord KP, Warner ME, Lennon RL, Conover MA, Jansson-Schumacher U. Role of preoperative cessation of smoking and other factors in postoperative pulmonary complications: a blinded prospective study of coronary artery bypass patients. Mayo Clinic proceedings. 1989;64(6):609-16.

82. Kuri M, Nakagawa M, Tanaka H, Hasuo S, Kishi Y. Determination of the duration of preoperative smoking cessation to improve wound healing after head and neck surgery. Anesthesiology. 2005;102(5):892-6.

83. Graham M, Purdy J, Emami B, Harms W, Bosch W, Lockett M et al. Clinical dose volume histogram analysis for pneumonitis after 3D treatment for non-small cell lung cancer (NSCLC). Int J Radiat Oncol Biol Phys. 1999;45:323-9.

84. Das S, Misra S, Munshi A, Rathod S, Purandare N, Tandon S et al. A prospective study to evaluate clinical radiation induced pneumonitis in lung cancer patients and its dose response relationship with radiotherapy. J Lung Cancer Diagn Treat. 2016;1:1.

85. Chun S, Hu C, Choy H, Komaki R, Timmerman R, Schild S et al. Impact of IntensityModulated Radiation Therapy Technique for Locally Advanced Non-Small-Cell Lung Cancer: A Secondary Analysis of the NRG Oncology RTOG 0617 Randomized Clinical Trial. J Clin Oncol. 2017;35:56-62.

86. Verma V, Shostrom V, Zhen W, Zhang M, Braunstein S, Holland J et al. Influence of Fractionation Scheme and Tumor Location on Toxicities After Stereotactic Body Radiation Therapy for Large ( $\geq 5 \mathrm{~cm}$ ) Non-Small Cell Lung Cancer: A Multi-institutional Analysis. Int J Radiat Oncol Biol Phys. 2017;97:778-85.

87. Verma V, Simone Cn, Allen P, Gajjar S, Shah C, Zhen W et al. Multi-Institutional Experience of Stereotactic Ablative Radiation Therapy for Stage I Small Cell Lung Cancer. Int J Radiat Oncol Biol Phys. 2017;97.

88. Rancati T, Ceresoli G, Gagliardi G, Schipani S, Cattaneo G. Factors predicting radiation pneumonitis in lung cancer patients: A retrospective study. Radiother Oncol. 2003;67:275-83. 89. Inoue T, Shiomi H, Oh R. Stereotactic body radiotherapy for Stage I lung cancer with chronic obstructive pulmonary disease: special reference to survival and radiation-induced pneumonitis. J Radiat Res. 2015;56:727-34.

90. Takeda A, Lunieda E, Ohashi T, Aoki Y, Oku Y, Enomoto T et al. Severe COPD is correlated with mild radiation pneumonitis following stereotactic body radiotherapy. Chest. 2012;141:858-66.

91. Wang J, Cao J, Yuan S, Ji W, Arenberg D, Dai J et al. Poor baseline pulmonary function may not increase the risk of radiation-induced lung toxicity. Int J Radiat Oncol Biol Phys. 2013;85:798-804.

92. Henkenberens C, Janssen S, Lavae-Mokhtari M, Leni K, Meyer A, Christiansen H et al. Inhalative steroids as an individual treatment in symptomatic lung cancer patients with radiation pneumonitis grade II after radiotherapy - a single-centre experience. Radiation Oncology. 2016;11:12. doi:10.1186/s13014-016-0580-3.

93. de Baere T, Tselikas L, Gravel G, Deschamps F. Lung ablation: Best practice/results/response assessment/role alongside other ablative therapies. Clinical radiology. 2017;72(8):657-64. doi:10.1016/j.crad.2017.01.005.

94. Mu L, Pan T, Lyu N, Sun L, Li S, Xie Q et al. CT-guided percutaneous radiofrequency ablation for lung neoplasms adjacent to the pericardium. Lung Cancer. 2018;122:25-31. doi:10.1016/j.lungcan.2018.05.004.

95. Gerard C, Debruyne C. Immunotherapy in the landscape of new targeted treatments for non-small cell lung cancer. Mol Oncol. 2009;3(5-6):409-24. doi:10.1016/j.molonc.2009.09.001. 
96. Shi L, Tang J, Tong L, Liu Z. Risk of interstitial lung disease with gefitinib and erlotinib in advanced non-small cell lung cancer: a systematic review and meta-analysis of clinical trials. Lung Cancer. 2014;83:231-9.

97. Pellegrino B, Facchinetti F, Bordi P, Silva M, Gnetti L, Tiseo M. Lung Toxicity in NonSmall-Cell Lung Cancer Patients Exposed to ALK Inhibitors: Report of a Peculiar Case and Systematic Review of the Literature. Clin Lung Cancer. 2017:pii: S1525-7304(17)30302-9.

98. Khunger M, Rakshit S, Pasupuleti V, Hernandez A, Mazzone P, Stevenson J et al. Incidence of Pneumonitis With Use of Programmed Death 1 and Programmed Death-Ligand 1 Inhibitors in Non-Small Cell Lung Cancer: A Systematic Review and Meta-Analysis of Trials. Chest. 2017;152:271-81.

99. Fujimoto D, Kato R, Morimoto T, Shimizu R, Sato Y, Kogo M et al. Characteristics and prognostic impact of pneumonitis during systemic anti-cancer therapy in patients with advanced non-small-cell lung cancer. PLoS One. 2016;11:e0168465.

100. Dimopoulou I, Bamias A, Lyberopoulos P, Dimopoulos M. Pulmonary toxicity from novel antineoplastic agents. Ann Oncol. 2006;17:372-9.

101. Msaad S, Yangui I, Bahloul N, Abid N, Koubaa M, Hentati Y et al. Do inhaled corticosteroids increase the risk of Pneumocystis pneumonia in people with lung cancer? World J Clin Cases. 2015;3:843-7.

102. Tsai S, Lin Y, Wu Y, Chu S, Wu C. Pulmonary Opportunistic Infections in A Lung Cancer patient treated by inhaled corticosteroid. J Intern Med Taiwan. 2009;20:92-6.

103. Wilkinson T. Immune checkpoints in chronic obstructive pulmonary disease. Eur Respir Rev. 2017;26:170045.

104. Sohal SS. Chronic Obstructive Pulmonary Disease (COPD) and Lung Cancer: Epithelial Mesenchymal Transition (EMT), the Missing Link? EBioMedicine. 2015;2(11):1578-9. doi:10.1016/j.ebiom.2015.10.016.

105. Barnes P, Adcock I. Chronic obstructive pulmonary disease and lung cancer: a lethal association. American journal of respiratory and critical care medicine. 2011;184(8):866 - 7.

106. Morlá M, Busquets X, Pons J, Sauleda J, MacNee W, Agustí AGN. Telomere shortening in smokers with and without COPD. European Respiratory Journal. 2006;27(3):525-8. doi:10.1183/09031936.06.00087005.

107. Ceylan E, Kocyigit A, Gencer M, Aksoy N, Selek S. Increased DNA damage in patients with chronic obstructive pulmonary disease who had once smoked or been exposed to biomass. Respiratory Medicine. 2006;100(7):1270-6. doi:https://doi.org/10.1016/j.rmed.2005.10.011. 108. Eapen MS, Sharma P, Moodley YP, Hansbro PM, Sohal SS. Dysfunctional Immunity and Microbial Adhesion Molecules in Smoking-Induced Pneumonia. American journal of respiratory and critical care medicine. 2018. doi:10.1164/rccm.201808-1553LE.

109. Eapen MS, Hansbro PM, McAlinden K, Kim RY, Ward C, Hackett TL et al. Abnormal M1/M2 macrophage phenotype profiles in the small airway wall and lumen in smokers and chronic obstructive pulmonary disease (COPD). Sci Rep. 2017;7(1):13392. doi:10.1038/s41598-017-13888-x.

110. Eapen MS, McAlinden K, Tan D, Weston S, Ward C, Muller HK et al. Profiling cellular and inflammatory changes in the airway wall of mild to moderate COPD. Respirology. 2017. doi:10.1111/resp.13021.

111. Eapen MS, Myers S, Walters EH, Sohal SS. Airway inflammation in chronic obstructive pulmonary disease (COPD): a true paradox. Expert Rev Respir Med. 2017;11(10):827-39. doi:10.1080/17476348.2017.1360769.

112. Bernardo I, Bozinovski S, Vlahos R. Targeting oxidant-dependent mechanisms for the treatment of COPD and its comorbidities. Pharmacology \& Therapeutics. 2015;155:60-79. doi:https://doi.org/10.1016/j.pharmthera.2015.08.005. 
113. Wang L-E, Gorlova OY, Ying J, Qiao Y, Weng S-F, Lee AT et al. Genome-Wide Association Study Reveals Novel Genetic Determinants of DNA Repair Capacity in Lung Cancer. Cancer Research. 2013;73(1):256-64. doi:10.1158/0008-5472.Can-12-1915.

114. Wei Q, Cheng L, Hong WK, Spitz MR. Reduced DNA Repair Capacity in Lung Cancer Patients. Cancer Research. 1996;56(18):4103-7.

115. Aoshiba K, Tsuji T, Yamaguchi K, Itoh M, Nakamura H. The danger signal plus DNA damage two-hit hypothesis for chronic inflammation in COPD. European Respiratory Journal. 2013;42(6):1689-95. doi:10.1183/09031936.00102912.

116. Freund A, Orjalo AV, Desprez P-Y, Campisi J. Inflammatory Networks during Cellular Senescence: Causes and Consequences. Trends in molecular medicine. 2010;16(5):238-46. doi:10.1016/j.molmed.2010.03.003.

117. Qu Z, Sun F, Zhou J, Li L, Shapiro SD, Xiao G. Interleukin-6 Prevents the Initiation but Enhances the Progression of Lung Cancer. Cancer Res. 2015;75(16):3209-15. doi:10.1158/0008-5472.Can-14-3042.

118. Ojo O, Lagan AL, Rajendran V, Spanjer A, Chen L, Sohal SS et al. Pathological changes in the COPD lung mesenchyme - Novel lessons learned from in vitro and in vivo studies. Pulmonary pharmacology \& therapeutics. 2014. doi:S1094-5539(14)00042-X [pii]

10.1016/j.pupt.2014.04.004.

119. Eapen MS, McAlinden K, Tan D, Weston S, Ward C, Muller HK et al. Profiling cellular and inflammatory changes in the airway wall of mild to moderate COPD. Respirology. 2017;22(6):1125-32. doi:doi:10.1111/resp.13021.

120. Eapen MS, Hansbro PM, McAlinden K, Kim RY, Ward C, Hackett T-L et al. Abnormal M1/M2 macrophage phenotype profiles in the small airway wall and lumen in smokers and chronic obstructive pulmonary disease (COPD). Scientific Reports. 2017;7(1):13392. doi:10.1038/s41598-017-13888-x.

121. Sohal SS, Reid D, Soltani A, Weston S, Muller HK, Wood-Baker R et al. Changes in Airway Histone Deacetylase2 in Smokers and COPD with Inhaled Corticosteroids: A Randomized Controlled Trial. PLoS One. 2013;8(5):e64833. doi:10.1371/journal.pone.0064833.

122. Stathopoulos GT, Sherrill TP, Han W, Sadikot RT, Yull FE, Blackwell TS et al. Host Nuclear Factor- $\kappa$ B Activation Potentiates Lung Cancer Metastasis. Molecular Cancer Research. 2008;6(3):364-71. doi:10.1158/1541-7786.Mcr-07-0309.

123. Eapen MS, Myers S, Walters EH, Sohal SS. Airway inflammation in chronic obstructive pulmonary disease (COPD): a true paradox. Expert Review of Respiratory Medicine. 2017;11(10):827-39. doi:10.1080/17476348.2017.1360769.

124. Kaku Y, Imaoka H, Morimatsu Y, Komohara Y, Ohnishi K, Oda H et al. Overexpression of CD163, CD204 and CD206 on Alveolar Macrophages in the Lungs of Patients with Severe Chronic Obstructive Pulmonary Disease. PLoS ONE. 2014;9(1):e87400. doi:10.1371/journal.pone.0087400.

125. Ma J, Liu L, Che G, Yu N, Dai F, You Z. The M1 form of tumor-associated macrophages in non-small cell lung cancer is positively associated with survival time. BMC Cancer. 2010;10(1):112. doi:10.1186/1471-2407-10-112.

126. Mei J, Xiao Z, Guo C, Pu Q, Ma L, Liu C et al. Prognostic impact of tumor-associated macrophage infiltration in non-small cell lung cancer: A systemic review and meta-analysis. Oncotarget. 2016;7(23):34217-28. doi:10.18632/oncotarget.9079.

127. Almatroodi SA, McDonald CF, Darby IA, Pouniotis DS. Characterization of M1/M2 Tumour-Associated Macrophages (TAMs) and Th1/Th2 Cytokine Profiles in Patients with NSCLC. Cancer microenvironment : official journal of the International Cancer Microenvironment Society. 2016;9(1):1-11. doi:10.1007/s 12307-015-0174-x. 
128. McKendry RT, Spalluto CM, Burke H, Nicholas B, Cellura D, Al-Shamkhani A et al. Dysregulation of Antiviral Function of CD8(+) T Cells in the Chronic Obstructive Pulmonary Disease Lung. Role of the PD-1-PD-L1 Axis. American journal of respiratory and critical care medicine. 2016;193(6):642-51. doi:10.1164/rccm.201504-0782OC.

129. Kamphorst AO, Pillai RN, Yang S, Nasti TH, Akondy RS, Wieland A et al. Proliferation of PD-1+ CD8 T cells in peripheral blood after PD-1-targeted therapy in lung cancer patients. Proceedings of the National Academy of Sciences of the United States of America. 2017;114(19):4993-8. doi:10.1073/pnas.1705327114.

130. Garon EB, Rizvi NA, Hui R, Leighl N, Balmanoukian AS, Eder JP et al. Pembrolizumab for the Treatment of Non-Small-Cell Lung Cancer. New England Journal of Medicine. 2015;372(21):2018-28. doi:10.1056/NEJMoa1501824.

131. Kubo H. Extracellular Vesicles in Lung Disease. Chest.153(1):210-6. doi:10.1016/j.chest.2017.06.026.

132. Fujita Y, Kosaka N, Araya J, Kuwano K, Ochiya T. Extracellular vesicles in lung microenvironment and pathogenesis. Trends in Molecular Medicine.21(9):533-42. doi:10.1016/j.molmed.2015.07.004.

133. Wu K, Xing F, Wu S-Y, Watabe K. Extracellular vesicles as emerging targets in cancer: Recent development from bench to bedside. Biochimica et Biophysica Acta (BBA) - Reviews on Cancer. 2017;1868(2):538-63. doi:https://doi.org/10.1016/j.bbcan.2017.10.001.

134. McCready J, Sims JD, Chan D, Jay DG. Secretion of extracellular hsp90 $\alpha$ via exosomes increases cancer cell motility: a role for plasminogen activation. BMC Cancer. 2010;10(1):294. doi:10.1186/1471-2407-10-294.

135. Hacker S, Lambers C, Hoetzenecker K, Pollreisz A, Aigner C, Lichtenauer M et al. Elevated HSP27, HSP70 and HSP90 alpha in chronic obstructive pulmonary disease: markers for immune activation and tissue destruction. Clinical laboratory. 2009;55(1-2):31-40.

136. Nagaraju GP, Long TE, Park W, Landry JC, Taliaferro-Smith L, Farris AB et al. Heat shock protein 90 promotes epithelial to mesenchymal transition, invasion, and migration in colorectal cancer. Molecular carcinogenesis. 2015;54(10):1147-58. doi:10.1002/mc.22185.

137. Brown D, Rahman M, Nana-Sinkam SP. MicroRNAs in Respiratory Disease. A Clinician's Overview. Annals of the American Thoracic Society. 2014;11(8):1277-85. doi:10.1513/AnnalsATS.201404-179FR.

138. Gregory PA, Bert AG, Paterson EL, Barry SC, Tsykin A, Farshid G et al. The miR-200 family and miR-205 regulate epithelial to mesenchymal transition by targeting ZEB1 and SIP1. Nature cell biology. 2008;10(5):593-601. doi:10.1038/ncb1722.

139. Lu M, Jolly MK, Levine H, Onuchic JN, Ben-Jacob E. MicroRNA-based regulation of epithelial-hybrid-mesenchymal fate determination. Proc Natl Acad Sci U S A. 2013;110(45):18144-9. doi:10.1073/pnas.1318192110.

140. Zaravinos A. The Regulatory Role of MicroRNAs in EMT and Cancer. Journal of Oncology. 2015;2015:865816. doi:10.1155/2015/865816.

141. Mongroo PS, Rustgi AK. The role of the miR-200 family in epithelial-mesenchymal transition. Cancer Biology \& Therapy. 2010;10(3):219-22. doi:10.4161/cbt.10.6312548.

142. Rabinowits G, Gercel-Taylor C, Day JM, Taylor DD, Kloecker GH. Exosomal microRNA: a diagnostic marker for lung cancer. Clin Lung Cancer. 2009;10(1):42-6. doi:10.3816/CLC.2009.n.006.

143. Sorokin L. The impact of the extracellular matrix on inflammation. Nat Rev Immunol. 2010;10(10):712-23. doi:10.1038/nri2852.

144. Burgstaller G, Oehrle B, Gerckens M, White ES, Schiller HB, Eickelberg O. The instructive extracellular matrix of the lung: basic composition and alterations in chronic lung disease. The European respiratory journal. 2017;50(1). doi:10.1183/13993003.01805-2016. 
145. Burgess JK, Mauad T, Tjin G, Karlsson JC, Westergren-Thorsson G. The Extracellular Matrix - the under-recognised element in lung disease? J Pathol. 2016. doi:10.1002/path.4808. 146. Frantz C, Stewart KM, Weaver VM. The extracellular matrix at a glance. J Cell Sci. 2010;123(Pt 24):4195-200. doi:10.1242/jcs.023820.

147. Sethi T, Rintoul RC, Moore SM, MacKinnon AC, Salter D, Choo C et al. Extracellular matrix proteins protect small cell lung cancer cells against apoptosis: a mechanism for small cell lung cancer growth and drug resistance in vivo. Nat Med. 1999;5(6):662-8. doi:10.1038/9511.

148. Whipple CA. Tumor talk: understanding the conversation between the tumor and its microenvironment. Cancer Cell Microenviron. 2015;2(2):e773. doi:10.14800/ccm.773.

149. Annoni R, Lancas T, Yukimatsu Tanigawa R, de Medeiros Matsushita M, de Morais Fernezlian S, Bruno A et al. Extracellular matrix composition in COPD. Eur Respir J. 2012;40(6):1362-73. doi:10.1183/09031936.00192611.

150. Hallgren O, Nihlberg K, Dahlback M, Bjermer L, Eriksson LT, Erjefalt JS et al. Altered fibroblast proteoglycan production in COPD. Respiratory research. 2010;11:55. doi:10.1186/1465-9921-11-55.

151. Larsson-Callerfelt AK, Hallgren O, Andersson-Sjoland A, Thiman L, Bjorklund J, Kron $\mathrm{J}$ et al. Defective alterations in the collagen network to prostacyclin in COPD lung fibroblasts. Respiratory research. 2013;14:21. doi:10.1186/1465-9921-14-21.

152. Willenbrock F, Crabbe T, Slocombe PM, Sutton CW, Docherty AJ, Cockett MI et al. The activity of the tissue inhibitors of metalloproteinases is regulated by $\mathrm{C}$-terminal domain interactions: a kinetic analysis of the inhibition of gelatinase A. Biochemistry. 1993;32(16):4330-7.

153. Polette M, Nawrocki-Raby B, Gilles C, Clavel C, Birembaut P. Tumour invasion and matrix metalloproteinases. Crit Rev Oncol Hematol. 2004;49(3):179-86. doi:10.1016/j.critrevonc.2003.10.008.

154. Djekic UV, Gaggar A, Weathington NM. Attacking the multi-tiered proteolytic pathology of COPD: new insights from basic and translational studies. Pharmacol Ther. 2009;121(2):13246. doi:10.1016/j.pharmthera.2008.09.008.

155. Murakami J, Ueda K, Sano F, Hayashi M, Nishimoto A, Hamano K. Pulmonary emphysema and tumor microenvironment in primary lung cancer. J Surg Res. 2016;200(2):690-7. doi:10.1016/j.jss.2015.09.004.

156. Theocharis AD, Gialeli C, Bouris P, Giannopoulou E, Skandalis SS, Aletras AJ et al. Cellmatrix interactions: focus on proteoglycan-proteinase interplay and pharmacological targeting in cancer. FEBS J. 2014;281(22):5023-42. doi:10.1111/febs.12927.

157. Mocchegiani E, Giacconi R, Costarelli L. Metalloproteases/anti-metalloproteases imbalance in chronic obstructive pulmonary disease: genetic factors and treatment implications. Curr Opin Pulm Med. 2011;17 Suppl 1:S11-9. doi:10.1097/01.mcp.0000410743.98087.12.

158. Sohal S, Reid D, Soltani A, Ward C, Weston S, Muller H et al. Reticular basement membrane fragmentation and potential epithelial mesenchymal transition is exaggerated in the airways of smokers with chronic obstructive pulmonary disease. Respirology. 2010;15(6):930 -8 .

159. Daijo H, Hoshino Y, Kai S, Suzuki K, Nishi K, Matsuo Y et al. Cigarette smoke reversibly activates hypoxia-inducible factor 1 in a reactive oxygen species-dependent manner. Sci Rep. 2016;6:34424. doi:10.1038/srep34424.

160. Zhang D, Li B, Shi J, Zhao L, Zhang X, Wang C et al. Suppression of tumor growth and metastasis by simultaneously blocking vascular endothelial growth factor (VEGF)-A and VEGF-C with a receptor-immunoglobulin fusion protein. Cancer Res. 2010;70(6):2495-503. doi:10.1158/0008-5472.CAN-09-3488. 
161. Zhang Q, Tang X, Zhang ZF, Velikina R, Shi S, Le AD. Nicotine induces hypoxiainducible factor-1alpha expression in human lung cancer cells via nicotinic acetylcholine receptor-mediated signaling pathways. Clin Cancer Res. 2007;13(16):4686-94. doi:10.1158/1078-0432.CCR-06-2898.

162. Harkness LM, Kanabar V, Sharma HS, Westergren-Thorsson G, Larsson-Callerfelt AK. Pulmonary vascular changes in asthma and COPD. Pulmonary pharmacology \& therapeutics. 2014;29(2):144-55. doi:10.1016/j.pupt.2014.09.003.

163. Bergers G, Benjamin LE. Tumorigenesis and the angiogenic switch. Nat Rev Cancer. 2003;3(6):401-10. doi:10.1038/nrc1093.

164. Kamlah F, Eul BG, Li S, Lang N, Marsh LM, Seeger W et al. Intravenous injection of siRNA directed against hypoxia-inducible factors prolongs survival in a Lewis lung carcinoma cancer model. Cancer Gene Ther. 2009;16(3):195-205. doi:10.1038/cgt.2008.71.

165. De Palma M, Biziato D, Petrova TV. Microenvironmental regulation of tumour angiogenesis. Nat Rev Cancer. 2017;17(8):457-74. doi:10.1038/nrc.2017.51.

166. Wang J, Ikeda R, Che XF, Ooyama A, Yamamoto M, Furukawa T et al. VEGF expression is augmented by hypoxiainduced PGIS in human fibroblasts. Int J Oncol. 2013;43(3):746-54. doi:10.3892/ijo.2013.1994.

167. Faner R, Cruz T, Lopez-Giraldo A, Agusti A. Network medicine, multimorbidity and the lung in the elderly. The European respiratory journal. 2014;44(3):775-88. doi:10.1183/09031936.00078714.

168. Siafakas NM, Antoniou KM, Tzortzaki EG. Role of angiogenesis and vascular remodeling in chronic obstructive pulmonary disease. Int J Chron Obstruct Pulmon Dis. 2007;2(4):453-62. 169. Westergren-Thorsson G, Bagher M, Andersson-Sjoland A, Thiman L, Lofdahl CG, Hallgren $\mathrm{O}$ et al. VEGF synthesis is induced by prostacyclin and TGF-beta in distal lung fibroblasts from COPD patients and control subjects: Implications for pulmonary vascular remodelling. Respirology. 2017. doi:10.1111/resp.13142.

170. Santos S, Peinado VI, Ramirez J, Morales-Blanhir J, Bastos R, Roca J et al. Enhanced expression of vascular endothelial growth factor in pulmonary arteries of smokers and patients with moderate chronic obstructive pulmonary disease. American journal of respiratory and critical care medicine. 2003;167(9):1250-6. doi:10.1164/rccm.200210-1233OC

200210-1233OC [pii].

171. Kanazawa H, Asai K, Hirata K, Yoshikawa J. Possible effects of vascular endothelial growth factor in the pathogenesis of chronic obstructive pulmonary disease. Am J Med. 2003;114(5):354-8. doi:S0002934302015620 [pii].

172. Valipour A, Schreder M, Wolzt M, Saliba S, Kapiotis S, Eickhoff P et al. Circulating vascular endothelial growth factor and systemic inflammatory markers in patients with stable and exacerbated chronic obstructive pulmonary disease. Clin Sci (Lond). 2008;115(7):225-32. doi:10.1042/CS20070382

CS20070382 [pii].

173. Kranenburg AR, de Boer WI, Alagappan VK, Sterk PJ, Sharma HS. Enhanced bronchial expression of vascular endothelial growth factor and receptors (Flk-1 and Flt-1) in patients with chronic obstructive pulmonary disease. Thorax. 2005;60(2):106-13. doi:60/2/106 [pii]

10.1136/thx.2004.023986.

174. Kranenburg AR, De Boer WI, Van Krieken JH, Mooi WJ, Walters JE, Saxena PR et al. Enhanced expression of fibroblast growth factors and receptor FGFR-1 during vascular remodeling in chronic obstructive pulmonary disease. American journal of respiratory cell and molecular biology. 2002;27(5):517-25. 
175. Kasahara Y, Tuder RM, Cool CD, Lynch DA, Flores SC, Voelkel NF. Endothelial cell death and decreased expression of vascular endothelial growth factor and vascular endothelial growth factor receptor 2 in emphysema. American journal of respiratory and critical care medicine. 2001;163(3 Pt 1):737-44. doi:10.1164/ajrccm.163.3.2002117.

176. Kasahara Y, Tuder RM, Taraseviciene-Stewart L, Le Cras TD, Abman S, Hirth PK et al. Inhibition of VEGF receptors causes lung cell apoptosis and emphysema. J Clin Invest. 2000;106(11):1311-9. doi:10.1172/JCI10259.

177. Greenberg JI, Shields DJ, Barillas SG, Acevedo LM, Murphy E, Huang J et al. A role for VEGF as a negative regulator of pericyte function and vessel maturation. Nature. 2008;456(7223):809-13. doi:nature07424 [pii]

10.1038/nature07424.

178. Segev A, Nili N, Strauss BH. The role of perlecan in arterial injury and angiogenesis. Cardiovasc Res. 2004;63(4):603-10. doi:10.1016/j.cardiores.2004.03.028.

179. Ashikari-Hada S, Habuchi H, Kariya Y, Kimata K. Heparin regulates vascular endothelial growth factor165-dependent mitogenic activity, tube formation, and its receptor phosphorylation of human endothelial cells. Comparison of the effects of heparin and modified heparins. J Biol Chem. 2005;280(36):31508-15. doi:10.1074/jbc.M414581200.

180. Tufvesson E, Westergren-Thorsson G. Biglycan and decorin induce morphological and cytoskeletal changes involving signalling by the small GTPases RhoA and Rac1 resulting in lung fibroblast migration. J Cell Sci. 2003;116(Pt 23):4857-64. doi:10.1242/jcs.00808.

181. Xing X, Gu X, Ma T, Ye H. Biglycan up-regulated vascular endothelial growth factor (VEGF) expression and promoted angiogenesis in colon cancer. Tumour Biol. 2015;36(3):1773-80. doi:10.1007/s13277-014-2779-y.

182. Amir Soltani HKM, Sukhwinder S. Sohal, David W. Reid, Steve Weston, Richard WoodBaker, E. Haydn Walters The distinctive characteristics of bronchial reticular basement membrane and vessel remodelling in chronic obstructive pulmonary disease (COPD) versus asthma: they are not the same disease. Histopathology. 2012; In press.

183. Sohal SS, Soltani A, Reid D, Ward C, Wills KE, Muller HK et al. A randomized controlled trial of inhaled corticosteroids (ICS) on markers of epithelial-mesenchymal transition (EMT) in large airway samples in COPD: an exploratory proof of concept study. Int J Chron Obstruct Pulmon Dis. 2014;9:533-42. doi:10.2147/copd.s63911.

184. Soltani A, Reid DW, Sohal SS, Wood-Baker R, Weston S, Muller HK et al. Basement membrane and vascular remodelling in smokers and chronic obstructive pulmonary disease: a cross-sectional study. Respiratory research. 2010;11:105. doi:1465-9921-11-105 [pii]

10.1186/1465-9921-11-105.

185. Soltani A, Sohal S, Reid D, Weston S, Wood-Baker R, Walters E. Vessel-associated transforming growth factor-Beta1 (TGF-beta1) is increased in the bronchial reticular basement membrane in COPD and normal smokers. PLoS One. 2012;7(6):e39736.

186. Soltani A, Wood-Baker R, Sohal SS, Muller HK, Reid D, Walters EH. Reticular Basement Membrane Vessels Are Increased in COPD Bronchial Mucosa by Both Factor VIII and Collagen IV Immunostaining and Are Hyperpermeable. J Allergy (Cairo). 2012;2012:958383. doi:10.1155/2012/958383.

187. Soltani A, Walters EH, Reid DW, Shukla SD, Nowrin K, Ward C et al. Inhaled corticosteroid normalizes some but not all airway vascular remodeling in COPD. Int J Chron Obstruct Pulmon Dis. 2016;11:2359-67. doi:10.2147/copd.s113176.

188. Sohal SS, Mahmood QM, Walters HE. Clinical significance of epithelial mesenchymal transition (EMT) in chronic obstructive pulmonary disease (COPD): potential target for prevention of airway fibrosis and lung cancer. Clinical and Translational Medicine. 2014;3(1):33. 
189. Herbst RS, Onn A, Sandler A. Angiogenesis and lung cancer: prognostic and therapeutic implications. J Clin Oncol. 2005;23(14):3243-56. doi:10.1200/JCO.2005.18.853.

190. Zoeller JJ, Whitelock JM, Iozzo RV. Perlecan regulates developmental angiogenesis by modulating the VEGF-VEGFR2 axis. Matrix Biol. 2009;28(5):284-91. doi:10.1016/j.matbio.2009.04.010.

191. Sharma B, Handler M, Eichstetter I, Whitelock JM, Nugent MA, Iozzo RV. Antisense targeting of perlecan blocks tumor growth and angiogenesis in vivo. The Journal of clinical investigation. 1998;102(8):1599-608. doi:10.1172/JCI3793.

192. Ding BS, Nolan DJ, Guo P, Babazadeh AO, Cao Z, Rosenwaks Z et al. Endothelialderived angiocrine signals induce and sustain regenerative lung alveolarization. Cell. 2011;147(3):539-53. doi:10.1016/j.cell.2011.10.003.

193. Franses JW, Baker AB, Chitalia VC, Edelman ER. Stromal endothelial cells directly influence cancer progression. Sci Transl Med. 2011;3(66):66ra5. doi:10.1126/scitranslmed.3001542.

194. Rooney C, Sethi T. The epithelial cell and lung cancer: the link between chronic obstructive pulmonary disease and lung cancer. Respiration. 2011;81(2):89-104. doi:10.1159/000323946.

195. Wu G, Luo J, Rana JS, Laham R, Sellke FW, Li J. Involvement of COX-2 in VEGFinduced angiogenesis via P38 and JNK pathways in vascular endothelial cells. Cardiovasc Res. 2006;69(2):512-9. doi:S0008-6363(05)00493-1 [pii]

10.1016/j.cardiores.2005.09.019.

196. Chen Y, Chen P, Hanaoka M, Droma Y, Kubo K. Enhanced levels of prostaglandin E2 and matrix metalloproteinase-2 correlate with the severity of airflow limitation in stable COPD. Respirology. 2008;13(7):1014-21. doi:10.1111/j.1440-1843.2008.01365.x.

197. Campa D, Zienolddiny S, Maggini V, Skaug V, Haugen A, Canzian F. Association of a common polymorphism in the cyclooxygenase 2 gene with risk of non-small cell lung cancer. Carcinogenesis. 2004;25(2):229-35. doi:10.1093/carcin/bgh008.

198. Ruan D, So SP. Prostaglandin E2 produced by inducible COX-2 and mPGES-1 promoting cancer cell proliferation in vitro and in vivo. Life Sci. 2014;116(1):43-50. doi:10.1016/j.lfs.2014.07.042.

199. Han S, Ritzenthaler JD, Wingerd B, Roman J. Activation of peroxisome proliferatoractivated receptor beta/delta (PPARbeta/delta) increases the expression of prostaglandin E2 receptor subtype EP4. The roles of phosphatidylinositol 3-kinase and CCAAT/enhancerbinding protein beta. J Biol Chem. 2005;280(39):33240-9. doi:10.1074/jbc.M507617200.

200. Liu F, Mih JD, Shea BS, Kho AT, Sharif AS, Tager AM et al. Feedback amplification of fibrosis through matrix stiffening and COX-2 suppression. J Cell Biol. 2010;190(4):693-706. doi:10.1083/jcb.201004082.

201. Yokouchi H, Kanazawa K. Revisiting the role of COX-2 inhibitor for non-small cell lung cancer. Transl Lung Cancer Res. 2015;4(5):660-4. doi:10.3978/j.issn.2218-6751.2015.04.03.

202. Houghton AM. Mechanistic links between COPD and lung cancer. Nature Reviews Cancer. 2013;13:233-45. doi:10.1038/nrc3477.

203. Yang IA, Holloway JW, Fong KM. Genetic susceptibility to lung cancer and comorbidities. Journal of Thoracic Disease. 2013;5. doi:10.3978/j.issn.2072-1439.2013.08.06.

204. Ziółkowska-Suchanek I, Mosor M, Gabryel P, Grabicki M, Zurawek M, Fichna M et al. Susceptibility loci in lung cancer and COPD: Association of IREB2 and FAM13A with pulmonary diseases. Scientific Reports. 2015;5:1-14. doi:10.1038/srep13502.

205. Dasgupta P, Rizwani W, Pillai S, Kinkade R, Kovacs M, Rastogi S et al. Nicotine induces cell proliferation, invasion and epithelial-mesenchymal transition in a variety of human cancer cell lines. Int J Cancer. 2009;124(1):36-45. doi:10.1002/ijc.23894. 
206. Zou W, Zou Y, Zhao Z, Li B, Ran P. Nicotine-induced epithelial-mesenchymal transition via Wnt/beta-catenin signaling in human airway epithelial cells. American journal of physiology Lung cellular and molecular physiology. 2013;304(4):L199-209. doi:10.1152/ajplung.00094.2012.

207. Durham AL, Adcock IM. The relationship between COPD and lung cancer. Lung Cancer. 2015;90:121-7. doi:10.1016/j.lungcan.2015.08.017.

208. Wauters E, Janssens W, Vansteenkiste J, Decaluwe H, Heulens N, Thienpont B et al. DNA methylation profiling of non-small cell lung cancer reveals a COPD-driven immune-related signature. Thorax. 2015;70(12):1113-22. doi:10.1136/thoraxjnl-2015-207288.

209. Sethi T. DNA methylation profiling of non-small cell lung cancer reveals a COPD-driven immune-related signature Thorax. 2015;70(12):1110-1. doi:10.1136/thoraxjnl-2015-207535. 210. Sohal SS. Airway Basal Cell Reprogramming and EMT: Potential Key to Understanding Early COPD. American journal of respiratory and critical care medicine. 2018. doi:10.1164/rccm.201712-2450LE.

211. George JT, Jolly MK, Xu S, Somarelli JA, Levine H. Survival Outcomes in Cancer Patients Predicted by a Partial EMT Gene Expression Scoring Metric. Cancer Research. 2017;77:6415-28. doi:10.1158/0008-5472.CAN-16-3521.

212. Tan TZ, Miow QH, Miki Y, Noda T, Mori S, Huang RY-j et al. Epithelial-mesenchymal transition spectrum quantification and its efficacy in deciphering survival and drug responses of cancer patients. EMBO Molecular Medicine. 2014;6:1279-93. doi:10.15252/emmm.201404208.

213. Jolly MK, Ward C, Eapen MS, Myers S, Hallgren O, Levine H et al. Epithelialmesenchymal transition, a spectrum of states: Role in lung development, homeostasis, and disease. Developmental Dynamics. 2017:1-13. doi:10.1002/dvdy.24541.

214. Mahmood MQ, Reid D, Ward C, Muller HK, Knight DA, Sohal SS et al. Transforming growth factor (TGF) $\beta 1$ and Smad signalling pathways: A likely key to EMT-associated COPD pathogenesis. Respirology. 2016:n/a-n/a. doi:10.1111/resp.12882.

215. Mahmood MQ, Sohal SS, Shukla SD, Ward C, Hardikar A, Noor WD et al. Epithelial mesenchymal transition in smokers: large versus small airways and relation to airflow obstruction. Int J Chron Obstruct Pulmon Dis. 2015;10:1515-24. doi:10.2147/copd.s81032.

216. Sohal S, Reid D, Soltani A, Ward C, Weston S, Muller H et al. Evaluation of epithelial mesenchymal transition in patients with chronic obstructive pulmonary disease. Respiratory research. 2011;12(1):130.

217. Sohal SS, Reid D, Soltani A, Ward C, Weston S, Muller HK et al. Reticular basement membrane fragmentation and potential epithelial mesenchymal transition is exaggerated in the airways of smokers with chronic obstructive pulmonary disease. Respirology. 2010;15(6):9308. doi:RES1808 [pii]

10.1111/j.1440-1843.2010.01808.x.

218. Sohal S, Walters E. Epithelial mesenchymal transition (EMT) in small airways of COPD patients. Thorax. 2013;68(8):783 - 4.

219. Mahmood MQ, Walters EH, Shukla SD, Weston S, Muller HK, Ward C et al. beta-catenin, Twist and Snail: Transcriptional regulation of EMT in smokers and COPD, and relation to airflow obstruction. Sci Rep. 2017;7(1):10832. doi:10.1038/s41598-017-11375-x.

220. Sohal SS, Walters EH. Advanced Non-Small-Cell Lung Cancer. The New England journal of medicine. 2017;377(20):1998-9. doi:10.1056/NEJMc1712794.

221. Sohal S, Walters E. Role of epithelial mesenchymal transition (EMT) in chronic obstructive pulmonary disease (COPD). Respiratory research. 2013;14(1):120.

222. Sohal SS, Hansbro PM, Walters EH. Epithelial Mesenchymal Transition in Chronic Obstructive Pulmonary Disease, a Precursor for Epithelial Cancers: Understanding and 
Translation to Early Therapy. Ann Am Thorac Soc. 2017;14(9):1491-2. doi:10.1513/AnnalsATS.201705-387LE.

223. Mahmood MQ, Ward C, Muller HK, Sohal SS, Walters EH. Epithelial mesenchymal transition (EMT) and non-small cell lung cancer (NSCLC): a mutual association with airway disease. Med Oncol. 2017;34(3):45. doi:10.1007/s12032-017-0900-y.

224. Sohal SS, Eapen MS, Ward C, Walters EH. Epithelial-Mesenchymal Transition: A Necessary New Therapeutic Target in Chronic Obstructive Pulmonary Disease? American journal of respiratory and critical care medicine. 2017;196(3):393-4. doi:10.1164/rccm.201704-0771LE.

225. Sohal SS, Walters EH. Essential need for rethink of COPD airway pathology: implications for new drug approaches for prevention of lung cancer as well as small airway fibrosis. Int $\mathbf{J}$ Chron Obstruct Pulmon Dis. 2017;12:2677-9. doi:10.2147/copd.s149092.

226. Eapen MS, Kota A, Vindin H, McAlinden KD, Xenaki D, Oliver BG et al. Apoptosis signal-regulating kinase 1 (ASK1) inhibition attenuates human airway smooth muscle growth and migration in chronic obstructive pulmonary disease (COPD). Clin Sci (Lond). 2018. doi:10.1042/cs20180398.

227. Nishioka M, Venkatesan N, Dessalle K, Mogas A, Kyoh S, Lin TY et al. Fibroblastepithelial cell interactions drive epithelial-mesenchymal transition differently in cells from normal and COPD patients. Respiratory Research. 2015;16:1-12. doi:10.1186/s12931-0150232-4.

228. Bocci F, Jolly MK, Tripathi SC, Aguilar M, Onuchic N, Hanash SM et al. Numb prevents a complete epithelial - mesenchymal transition by modulating Notch signalling. Journal of Royal Society Interface. 2017;14:20170512.

229. Murray LA, Dunmore R, Camelo A, Da Silva CA, Gustavsson MJ, Habiel DM et al. Acute cigarette smoke exposure activates apoptotic and inflammatory programs but a second stimulus is required to induce epithelial to mesenchymal transition in COPD epithelium. Respiratory Research. 2017;18:1-12. doi:10.1186/s12931-017-0565-2.

230. Jia D, Jolly MK, Tripathi SC, Hollander PD, Huang B, Lu M et al. Distinguishing Mechanisms Underlying EMT Tristability. Cancer Convergence. 2017;1:2. doi:10.1101/098962.

231. Leroy P, Mostov KE. Slug Is Required for Cell Survival during Partial EpithelialMesenchymal Transition of HGF-induced tubulogenesis. Journal of cell science. 2007;18:1943-52. doi:10.1091/mbc.E06.

232. Giacomelli C, Daniele S, Romei C, Tavanti L, Neri T, Piano I et al. The A2B Adenosine Receptor Modulates the Epithelial- Mesenchymal Transition through the Balance of cAMP/PKA and MAPK/ERK Pathway Activation in Human Epithelial Lung Cells. Frontiers in Pharmacology. 2018;9:1-18. doi:10.3389/fphar.2018.00054.

233. Jolly MK, Boareto M, Debeb BG, Aceto N, Farach-Carson MC, Woodward WA et al. Inflammatory breast cancer: a model for investigating cluster-based dissemination. npj Breast Cancer. 2017;3:21. doi:10.1038/s41523-017-0023-9.

234. Dang TT, Esparza MA, Maine EA, Westcott JM, Pearson GW. DeltaNp63alpha Promotes Breast Cancer Cell Motility through the Selective Activation of Components of the Epithelialto-Mesenchymal Transition Program. Cancer Res. 2015;75(18):3925-35. doi:10.1158/00085472.Can-14-3363.

235. Fustaino V, Presutti D, Colombo T, Cardinali B, Papoff G, Brandi R et al. Characterization of epithelial-mesenchymal transition intermediate/hybrid phenotypes associated to resistance to EGFR inhibitors in non-small cell lung cancer cell lines. Oncotarget. 2017;8:103340-63. doi:10.18632/oncotarget.21132. 
236. Jolly MK, Jia D, Boareto M, Mani SA, Pienta KJ, Ben-Jacob E et al. Coupling the modules of EMT and stemness : A tunable 'stemness window' model. Oncotarget. 2015;6:25161-74. doi:10.18632/oncotarget.4629.

237. Grosse-Wilde A, Fouquier d' Herouei A, McIntosh E, Ertaylan G, Skupin A, Kuestner RE et al. Stemness of the hybrid epithelial/mesenchymal state in breast cancer and its association with poor survival. PloS one. 2015;10:e0126522. doi:10.1371/journal.pone.0126522.

238. Jolly MK, Boareto M, Huang B, Jia D, Lu M, Ben-Jacob E et al. Implications of the Hybrid Epithelial/Mesenchymal Phenotype in Metastasis. Front Oncol. 2015;5:155. doi:10.3389/fonc.2015.00155.

239. Eapen MS, Myers S, Lu W, Tanghe C, Sharma P, Sohal SS. sE-cadherin and sVE-cadherin indicate active epithelial/endothelial to mesenchymal transition (EMT and EndoMT) in smokers and COPD: implications for new biomarkers and therapeutics. Biomarkers : biochemical indicators of exposure, response, and susceptibility to chemicals. 2018:1-5. doi:10.1080/1354750x.2018.1479772.

240. Kovacic JC, Mercader N, Torres M, Boehm M, Fuster V. Epithelial-to-mesenchymal and endothelial-to-mesenchymal transition: from cardiovascular development to disease. Circulation. 2012;125(14):1795-808. doi:10.1161/circulationaha.111.040352.

241. Piera-Velazquez S, Li Z, Jimenez SA. Role of endothelial-mesenchymal transition (EndoMT) in the pathogenesis of fibrotic disorders. Am J Pathol. 2011;179(3):1074-80. doi:10.1016/j.ajpath.2011.06.001.

242. Zeisberg EM, Potenta S, Xie L, Zeisberg M, Kalluri R. Discovery of endothelial to mesenchymal transition as a source for carcinoma-associated fibroblasts. Cancer Res. 2007;67(21):10123-8. doi:10.1158/0008-5472.can-07-3127.

243. Lin F, Wang N, Zhang TC. The role of endothelial-mesenchymal transition in development and pathological process. IUBMB Life. 2012;64(9):717-23. doi:10.1002/iub.1059.

244. Rieder F, Kessler SP, West GA, Bhilocha S, de la Motte C, Sadler TM et al. Inflammationinduced endothelial-to-mesenchymal transition: a novel mechanism of intestinal fibrosis. Am J Pathol. 2011;179(5):2660-73. doi:10.1016/j.ajpath.2011.07.042.

245. Gurzu S, Turdean S, Kovecsi A, Contac AO, Jung I. Epithelial-mesenchymal, mesenchymal-epithelial, and endothelial-mesenchymal transitions in malignant tumors: An update. World J Clin Cases. 2015;3(5):393-404. doi:10.12998/wjcc.v3.i5.393.

246. Welch-Reardon KM, Wu N, Hughes CC. A role for partial endothelial-mesenchymal transitions in angiogenesis? Arteriosclerosis, thrombosis, and vascular biology. 2015;35(2):303-8. doi:10.1161/atvbaha.114.303220.

247. Sohal SS. Endothelial to mesenchymal transition (EndMT): An active process in Chronic Obstructive Pulmonary Disease (COPD)? Respiratory Research. 2016;17:4-7. doi:10.1186/s12931-016-0337-4.

248. Sohal SS. Epithelial and endothelial cell plasticity in chronic obstructive pulmonary disease (COPD). Respir Investig. 2017;55(2):104-13. doi:10.1016/j.resinv.2016.11.006.

249. Choi SH, Nam JK, Kim BY, Jang J, Jin YB, Lee HJ et al. HSPB1 inhibits the endothelialto-mesenchymal transition to suppress pulmonary fibrosis and lung tumorigenesis. Cancer Research. 2016;76:1019-30. doi:10.1158/0008-5472.CAN-15-0952.

250. Potenta S, Zeisberg E, Kalluri R. The role of endothelial-to-mesenchymal transition in cancer progression. British Journal of Cancer. 2008;99:1375-9. doi:10.1038/sj.bjc.6604662.

251. Potenta S, Zeisberg E, Kalluri R. The role of endothelial-to-mesenchymal transition in cancer progression. Br J Cancer. 2008;99(9):1375-9. doi:10.1038/sj.bjc.6604662.

252. Sakao S, Voelkel NF, Tatsumi K. The vascular bed in COPD: pulmonary hypertension and pulmonary vascular alterations. Eur Respir Rev. 2014;23(133):350-5. doi:10.1183/09059180.00007913. 
253. Soltani A, Muller H, Sohal S, Reid D, Weston S, Wood-Baker R et al. Distinctive characteristics of bronchial reticular basement membrane and vessel remodelling in chronic obstructive pulmonary disease (COPD) and in asthma: they are not the same disease. Histopathology. 2012;60(6):964 - 70.

254. Soltani A, Sohal SS, Reid D, Weston S, Muller HK, Wood-Baker R et al. Basement membrane remodelling in COPD responds to inhaled corticosteroids. The Thoracic Society of Australia \& New Zealand Annual Scientific Meeting; 2010; Brisbane, Australia2010.

255. Soltani A, Sohal SS, Reid D, Weston S, Wood-Baker R, Walters EH. Vessel-associated transforming growth factor-beta1 (TGF-\&\#946 1) is increased in the bronchial reticular basement membrane in COPD and normal smokers. PLoS One. 2012;7(6):1-5. doi:10.1371/journal.pone.0039736.

256. Zanini A, Chetta A, Imperatori AS, Spanevello A, Olivieri D. The role of the bronchial microvasculature in the airway remodelling in asthma and COPD. Respiratory research. 2010;11:132. doi:10.1186/1465-9921-11-132.

257. Barbera JA, Peinado VI, Santos S. Pulmonary hypertension in chronic obstructive pulmonary disease. The European respiratory journal. 2003;21(5):892-905.

258. Reimann S, Fink L, Wilhelm J, Hoffmann J, Bednorz M, Seimetz M et al. Increased S100A4 expression in the vasculature of human COPD lungs and murine model of smokeinduced emphysema. Respiratory research. 2015;16:127. doi:10.1186/s12931-015-0284-5.

259. Coll-Bonfill N, Musri MM, Ivo V, Barbera JA, Tura-Ceide O. Transdifferentiation of endothelial cells to smooth muscle cells play an important role in vascular remodelling. Am J Stem Cells. 2015;4(1):13-21.

260. Watanabe K, Villarreal-Ponce A, Sun P, Salmans ML, Fallahi M, Andersen B et al. Mammary morphogenesis and regeneration require the inhibition of EMT at terminal end buds by ovol2 transcriptional repressor. Developmental Cell. 2014;29:59-74. doi:10.1016/j.devcel.2014.03.006.

261. Jolly MK, Tripathi SC, Jia D, Mooney SM, Celiktas M, Hanash SM et al. Stability of the hybrid epithelial/mesenchymal phenotype. Oncotarget. 2016;7:27067-84.

262. Hong T, Watanabe K, Ta CH, Villarreal-Ponce A, Nie Q, Dai X. An Ovol2-Zeb1 Mutual Inhibitory Circuit Governs Bidirectional and Multi-step Transition between Epithelial and Mesenchymal States. PLOS Computational Biology. 2015;11:e1004569. doi:10.1371/journal.pcbi.1004569.

263. Regan ER, Aird WC. Dynamical systems approach to endothelial heterogeneity. Circulation research. 2012;111:110-30. doi:10.1161/CIRCRESAHA.111.261701.

264. Jolly MK, Ware KE, Gilja S, Somarelli JA, Levine H. EMT and MET : necessary or permissive for metastasis ? Molecular Oncology. 2017;11:755-69. doi:10.1002/18780261.12083.

265. Cheung KJ, Ewald AJ. Illuminating breast cancer invasion: diverse roles for cell-cell interactions. Current Opinion in Cell Biol. 2015:99-111. doi:10.1016/j.ceb.2014.07.003.Illuminating.

266. Jones B, Donovan C, Liu G, Gomez HM, Chimankar V, Harrison CL et al. Animal models of COPD: What do they tell us? Respirology. 2017;22(1):21-32. doi:10.1111/resp.12908.

267. Beckett EL, Stevens RL, Jarnicki AG, Kim RY, Hanish I, Hansbro NG et al. A new shortterm mouse model of chronic obstructive pulmonary disease identifies a role for mast cell tryptase in pathogenesis. The Journal of allergy and clinical immunology. 2013;131(3):752-62. doi:10.1016/j.jaci.2012.11.053.

268. Hansbro PM, Hamilton MJ, Fricker M, Gellatly SL, Jarnicki AG, Zheng D et al. Importance of mast cell Prss31/transmembrane tryptase/tryptase-gamma in lung function and experimental chronic obstructive pulmonary disease and colitis. $J$ Biol Chem. 2014;289(26):18214-27. doi:10.1074/jbc.M114.548594. 
269. Haw TJ, Starkey MR, Nair PM, Pavlidis S, Liu G, Nguyen DH et al. A pathogenic role for tumor necrosis factor-related apoptosis-inducing ligand in chronic obstructive pulmonary disease. Mucosal immunology. 2016;9(4):859-72. doi:10.1038/mi.2015.111.

270. Churg A, Cosio M, Wright JL. Mechanisms of cigarette smoke-induced COPD: insights from animal models. American journal of physiology Lung cellular and molecular physiology. 2008;294(4):L612-31. doi:10.1152/ajplung.00390.2007.

271. Gaschler GJ, Bauer CM, Zavitz CC, Stampfli MR. Animal models of chronic obstructive pulmonary disease exacerbations. Contributions to microbiology. 2007;14:126-41. doi:10.1159/0000107059.

272. Hautamaki RD, Kobayashi DK, Senior RM, Shapiro SD. Requirement for macrophage elastase for cigarette smoke-induced emphysema in mice. Science. 1997;277(5334):2002-4.

273. Bazett M, Biala A, Huff RD, Zeglinksi MR, Hansbro PM, Bosiljcic M et al. Attenuating immune pathology using a microbial-based intervention in a mouse model of cigarette smokeinduced lung inflammation. Respiratory Research. 2017;18:92. doi:10.1186/s12931-017-0577y.

274. Hsu AC, Starkey MR, Hanish I, Parsons K, Haw TJ, Howland LJ et al. Targeting PI3Kp110alpha Suppresses Influenza Virus Infection in Chronic Obstructive Pulmonary Disease. American journal of respiratory and critical care medicine. 2015;191(9):1012-23. doi:10.1164/rccm.201501-01880C.

275. Liu G, Cooley MA, Jarnicki AG, Hsu ACY, Nair PM, Haw TJ et al. Fibulin-1 regulates the pathogenesis of tissue remodeling in respiratory diseases. JCI Insight. 2016;1(9):e86380. doi:10.1172/jci.insight.86380.

276. Kedzierski L, Tate MD, Hsu AC, Kolesnik TB, Linossi EM, Dagley L et al. Suppressor of cytokine signaling (SOCS)5 ameliorates influenza infection via inhibition of EGFR signaling. eLife. 2017;6:e20444. doi:10.7554/eLife.20444.

277. Hsu AC, Dua K, Starkey MR, Haw TJ, Nair PM, Nichol K et al. MicroRNA-125a and -b inhibit A20 and MAVS to promote inflammation and impair antiviral response in COPD. JCI Insight. 2017;2(7):e90443. doi:10.1172/jci.insight.90443.

278. Fricker M, Goggins BJ, Mateer S, Jones B, Kim RY, Gellatly SL et al. Chronic cigarette smoke exposure induces systemic hypoxia that drives intestinal dysfunction. JCI Insight. 2018;3(3). doi:10.1172/jci.insight.94040.

279. Jarnicki AG, Schilter H, Liu G, Wheeldon K, Essilfie AT, Foot JS et al. The inhibitor of semicarbazide-sensitive amine oxidase, PXS-4728A, ameliorates key features of chronic obstructive pulmonary disease in a mouse model. British journal of pharmacology. 2016;173(22):3161-75. doi:10.1111/bph.13573.

280. Moheimani F, Roth HM, Cross J, Reid AT, Shaheen F, Warner SM et al. Disruption of beta-catenin/CBP signaling inhibits human airway epithelial-mesenchymal transition and repair. The international journal of biochemistry \& cell biology. 2015;68:59-69. doi:10.1016/j.biocel.2015.08.014.

281. Barnes PJ. New anti-inflammatory targets for chronic obstructive pulmonary disease. Nature reviews Drug discovery. 2013;12(7):543-59.

282. Churg A, Wang RD, Tai H, Wang X, Xie C, Wright JL. Tumor necrosis factor-alpha drives $70 \%$ of cigarette smoke-induced emphysema in the mouse. American journal of respiratory and critical care medicine. 2004;170(5):492-8. doi:10.1164/rccm.200404-511OC. 283. D'Hulst A I, Bracke KR, Maes T, De Bleecker JL, Pauwels RA, Joos GF et al. Role of tumour necrosis factor-alpha receptor $\mathrm{p} 75$ in cigarette smoke-induced pulmonary inflammation and emphysema. The European respiratory journal. 2006;28(1):102-12. doi:10.1183/09031936.06.00059305. 
284. Hansbro PM, Kim RY, Starkey MR, Donovan C, Dua K, Mayall JR et al. Mechanisms and treatments for severe, steroid-resistant allergic airway disease and asthma. Immunological reviews. 2017;278(1):41-62. doi:10.1111/imr.12543.

285. Duong C, Seow HJ, Bozinovski S, Crack PJ, Anderson GP, Vlahos R. Glutathione peroxidase- 1 protects against cigarette smoke-induced lung inflammation in mice. American journal of physiology Lung cellular and molecular physiology. 2010;299(3):L425-33. doi:10.1152/ajplung.00038.2010.

286. Andrews CS, Matsuyama S, Lee B-C, Li J-D. Resveratrol suppresses NTHi-induced inflammation via up-regulation of the negative regulator MyD88 short. Scientific Reports. 2016;6:34445. doi:10.1038/srep34445

https://www.nature.com/articles/srep34445\#supplementary-information.

287. Medicherla S, Fitzgerald MF, Spicer D, Woodman P, Ma JY, Kapoun AM et al. p38alphaselective mitogen-activated protein kinase inhibitor SD-282 reduces inflammation in a subchronic model of tobacco smoke-induced airway inflammation. The Journal of pharmacology and experimental therapeutics. 2008;324(3):921-9. doi:10.1124/jpet.107.127092.

288. Johnson GL, Lapadat R. Mitogen-activated protein kinase pathways mediated by ERK, JNK, and p38 protein kinases. Science. 2002;298(5600):1911-2. doi:10.1126/science.1072682. 289. Meja KK, Seldon PM, Nasuhara Y, Ito K, Barnes PJ, Lindsay MA et al. p38 MAP kinase and MKK-1 co-operate in the generation of GM-CSF from LPS-stimulated human monocytes by an NF-kappa B-independent mechanism. British journal of pharmacology. 2000;131(6):1143-53. doi:10.1038/sj.bjp.0703684.

290. Kim RY, Horvat JC, Pinkerton JW, Starkey MR, Essilfie AT, Mayall JR et al. MicroRNA21 drives severe, steroid-insensitive experimental asthma by amplifying phosphoinositide 3kinase-mediated suppression of histone deacetylase 2 . The Journal of allergy and clinical immunology. 2017;139(2):519-32. doi:10.1016/j.jaci.2016.04.038.

291. Duan W, Aguinaldo Datiles AM, Leung BP, Vlahos CJ, Wong WS. An anti-inflammatory role for a phosphoinositide 3-kinase inhibitor LY294002 in a mouse asthma model. International immunopharmacology. 2005;5(3):495-502. doi:10.1016/j.intimp.2004.10.015.

292. Thomas MJ, Smith A, Head DH, Milne L, Nicholls A, Pearce W et al. Airway inflammation: chemokine-induced neutrophilia and the class I phosphoinositide 3-kinases. European journal of immunology. 2005;35(4):1283-91. doi:10.1002/eji.200425634.

293. Owen CA. Roles for proteinases in the pathogenesis of chronic obstructive pulmonary disease. Int J Chron Obstruct Pulmon Dis. 2008;3(2):253-68.

294. Walters EH, Reid D, Soltani A, Ward C. Angiogenesis: a potentially critical part of remodelling in chronic airway diseases? Pharmacol Ther. 2008;118(1):128-37. doi:S01637258(08)00021-1 [pii]

10.1016/j.pharmthera.2008.01.007.

295. Budden KF, Gellatly SL, Wood DL, Cooper MA, Morrison M, Hugenholtz P et al. Emerging pathogenic links between microbiota and the gut-lung axis. Nature reviews Microbiology. 2017;15(1):55-63. doi:10.1038/nrmicro.2016.142.

296. Kim RY, Pinkerton JW, Gibson PG, Cooper MA, Horvat JC, Hansbro PM. Inflammasomes in COPD and neutrophilic asthma. Thorax. 2015;70(12):1199-201. doi:10.1136/thoraxjnl-2014-206736.

297. Kim RY, Pinkerton JW, Essilfie AT, Robertson AAB, Baines KJ, Brown AC et al. Role for NLRP3 Inflammasome-mediated, IL-1beta-Dependent Responses in Severe, SteroidResistant Asthma. American journal of respiratory and critical care medicine. 2017;196(3):283-97. doi:10.1164/rccm.201609-1830OC. 
298. Shukla SD, Budden KF, Neal R, Hansbro PM. Microbiome effects on immunity, health and disease in the lung. Clinical \& translational immunology. 2017;6(3):e133. doi:10.1038/cti.2017.6.

299. Mateer SW, Maltby S, Marks E, Foster PS, Horvat JC, Hansbro PM et al. Potential mechanisms regulating pulmonary pathology in inflammatory bowel disease. Journal of leukocyte biology. 2015;98(5):727-37. doi:10.1189/jlb.3RU1114-563R.

300. Starkey MR, Jarnicki AG, Essilfie A-T, Gellatly SL, Kim RY, Brown AC et al. Murine models of infectious exacerbations of airway inflammation. Curr Opin Pharmacol. 2013;13(3):337-44. doi:10.1016/j.coph.2013.03.005.

301. Memon AA, Jakobsen S, Dagnaes-Hansen F, Sorensen BS, Keiding S, Nexo E. Positron emission tomography (PET) imaging with [11C]-labeled erlotinib: a micro-PET study on mice with lung tumor xenografts. Cancer Research. 2009;69(3):873-8. doi:10.1158/0008-5472.can08-3118.

302. Steiner P, Joynes C, Bassi R, Wang S, Tonra JR, Hadari YR et al. Tumor Growth Inhibition with Cetuximab and Chemotherapy in Non-Small Cell Lung Cancer Xenografts Expressing Wild-type and Mutated Epidermal Growth Factor Receptor. Clinical Cancer Research. 2007;13(5):1540-51. doi:10.1158/1078-0432.ccr-06-1887.

303. Sakuma Y, Matsukuma S, Nakamura Y, Yoshihara M, Koizume S, Sekiguchi H et al. Enhanced autophagy is required for survival in EGFR-independent EGFR-mutant lung adenocarcinoma cells. Laboratory Investigation. 2013;93:1137. doi:10.1038/labinvest.2013.102.

304. Akhtar S, Meeran SM, Katiyar N, Katiyar SK. Grape Seed Proanthocyanidins Inhibit the Growth of Human Non-Small Cell Lung Cancer Xenografts by Targeting Insulin-Like Growth Factor Binding Protein-3, Tumor Cell Proliferation, and Angiogenic Factors. Clinical Cancer Research. 2009;15(3):821-31. doi:10.1158/1078-0432.ccr-08-1901.

305. McLemore TL, Liu MC, Blacker PC, Gregg M, Alley MC, Abbott BJ et al. Novel Intrapulmonary Model for Orthotopic Propagation of Human Lung Cancers in Athymic Nude Mice. Cancer Research. 1987;47(19):5132-40.

306. Yamori T, Sato S, Chikazawa H, Kadota T. Anti-tumor Efficacy of Paclitaxel against Human Lung Cancer Xenografts. Japanese Journal of Cancer Research. 1997;88(12):1205-10. doi:10.1111/j.1349-7006.1997.tb00350.x.

307. Dong X, Guan J, English JC, Flint J, Yee J, Evans K et al. Patient-Derived First Generation Xenografts of Non-Small Cell Lung Cancers: Promising Tools for Predicting Drug Responses for Personalized Chemotherapy. Clinical Cancer Research. 2010;16(5):1442-51. doi:10.1158/1078-0432.ccr-09-2878.

308. Meuwissen R, Berns A. Mouse models for human lung cancer. Genes \& development. 2005;19(6):643-64.

309. Hodgkinson CL, Morrow CJ, Li Y, Metcalf RL, Rothwell DG, Trapani F et al. Tumorigenicity and genetic profiling of circulating tumor cells in small-cell lung cancer. Nat Med. 2014;20(8):897-903. doi:10.1038/nm.3600.

310. Cohen MH, Williams GA, Sridhara R, Chen G, McGuinn WD, Jr., Morse D et al. United States Food and Drug Administration Drug Approval summary: Gefitinib (ZD1839; Iressa) tablets. Clin Cancer Res. 2004;10(4):1212-8.

311. Thatcher N, Chang A, Parikh P, Rodrigues Pereira J, Ciuleanu T, von Pawel J et al. Gefitinib plus best supportive care in previously treated patients with refractory advanced nonsmall-cell lung cancer: results from a randomised, placebo-controlled, multicentre study (Iressa Survival Evaluation in Lung Cancer). Lancet (London, England). 2005;366(9496):1527-37. doi:10.1016/s0140-6736(05)67625-8.

312. Memon AA, Jakobsen S, Dagnaes-Hansen F, Sorensen BS, Keiding S, Nexo E. Positron emission tomography (PET) imaging with [11C]-labeled erlotinib: a micro-PET study on mice 
with lung tumor xenografts. Cancer Res. 2009;69(3):873-8. doi:10.1158/0008-5472.can-083118.

313. Perez-Soler R. The Role of Erlotinib (Tarceva, OSI 774) in the Treatment of Non-Small Cell Lung Cancer. Clinical Cancer Research. 2004;10(12):4238s-40s. doi:10.1158/10780432.ccr-040017.

314. Soda M, Takada S, Takeuchi K, Choi YL, Enomoto M, Ueno T et al. A mouse model for EML4-ALK-positive lung cancer. Proceedings of the National Academy of Sciences. 2008;105(50):19893-7. doi:10.1073/pnas.0805381105.

315. Gerber DE, Minna JD. ALK Inhibition for Non-Small Cell Lung Cancer: From Discovery to Therapy in Record Time. Cancer Cell. 2010;18(6):548-51. doi:https://doi.org/10.1016/j.ccr.2010.11.033.

316. B. Zhao SM, S. Chua et al., "Transgenicmouse models for lung cancer," Experimental Lung Research, vol. 26, no. 8, pp. 567-579, 2000.

317. Ji H, Li D, Chen L, Shimamura T, Kobayashi S, McNamara K et al. The impact of human EGFR kinase domain mutations on lung tumorigenesis and in vivo sensitivity to EGFRtargeted therapies. Cancer Cell. 2006;9(6):485-95. doi:10.1016/j.ccr.2006.04.022.

318. Sakai Y, Sasahira T, Ohmori H, Yoshida K, Kuniyasu H. Conjugated linoleic acid reduced metastasized LL2 tumors in mouse peritoneum. Virchows Archiv. 2006;449(3):341-7. doi:10.1007/s00428-006-0249-7.

319. Stoner GD, Greisiger EA, Schut HAJ, Pereira MA, Loeb TR, Klaunig JE et al. A comparison of the lung adenoma response in strain A/J mice after intraperitoneal and oral administration of carcinogens. Toxicology and applied pharmacology. 1984;72(2):313-23. doi:https://doi.org/10.1016/0041-008X(84)90316-8.

320. Takahashi H, Ogata H, Nishigaki R, Broide DH, Karin M. Tobacco Smoke Promotes Lung Tumorigenesis by Triggering IKK $\beta$ - and JNK1-Dependent Inflammation. Cancer Cell. 2010;17(1):89-97. doi:https://doi.org/10.1016/j.ccr.2009.12.008.

321. Rehm S, Lijinsky W, Singh G, Katyal SL. Mouse bronchiolar cell carcinogenesis. Histologic characterization and expression of Clara cell antigen in lesions induced by $\mathrm{N}$ nitrosobis-(2-chloroethyl) ureas. The American journal of pathology. 1991;139(2):413.

322. de Seranno S, Meuwissen R. Progress and applications of mouse models for human lung cancer. European Respiratory Journal. 2010;35(2):426-43.

323. Nikitin AY, Alcaraz A, Anver MR, Bronson RT, Cardiff RD, Dixon D et al. Classification of Proliferative Pulmonary Lesions of the Mouse. Cancer research. 2004;64(7):2307-16.

324. Witschi H, Espiritu I, Peake JL, Wu K, Maronpot RR, Pinkerton KE. The carcinogenicity of environmental tobacco smoke. Carcinogenesis. 1997;18(3):575-86.

325. Shimkin MB, Stoner GD. Lung tumors in mice: application to carcinogenesis bioassay. Advances in cancer research. 1975;21:1-58.

326. Malkinson AM. Primary lung tumors in mice as an aid for understanding, preventing, and treating human adenocarcinoma of the lung. Lung Cancer. 2001;32(3):265-79.

327. Malkinson AM. Genetic studies on lung tumor susceptibility and histogenesis in mice. Environmental Health Perspectives. 1991;93:149.

328. Beer DG, Malkinson AM. Genetic Influence on Type 2 or Clara Cell Origin of Pulmonary Adenomas in Urethan-Treated Mice 2 3. JNCI: Journal of the National Cancer Institute. 1985;75(5):963-9.

329. Wang Y, Zhang Z, Yan Y, Lemon WJ, LaRegina M, Morrison C et al. A Chemically Induced Model for Squamous Cell Carcinoma of the Lung in Mice. Cancer research. 2004;64(5):1647-54.

330. Dooley AL, Winslow MM, Chiang DY, Banerji S, Stransky N, Dayton TL et al. Nuclear factor I/B is an oncogene in small cell lung cancer. Genes \& development. 2011;25(14):14705 . 
331. Park K-S, Liang M-C, Raiser DM, Zamponi R, Roach RR, Curtis SJ et al. Characterization of the cell of origin for small cell lung cancer. Cell cycle. 2011;10(16):2806-15.

332. de Torres J, Marin J, Casanova C, Cote C, Carrizo S, Cordoba-Lanus E et al. Lung cancer in patients with chronic obstructive pulmonary disease- incidence and predicting factors. American journal of respiratory and critical care medicine. 2011;184(8):913 - 9. 